\title{
Cannabinoid exposure as a major driver of pediatric acute lymphoid Leukaemia rates across the USA: combined geospatial, multiple imputation and causal inference study
}

Albert Stuart Reece ${ }^{1,2^{*}}$ (D) and Gary Kenneth Hulse ${ }^{1,2}$

\begin{abstract}
Background: Acute lymphoid leukaemia (ALL) is the commonest childhood cancer whose incidence is rising in many nations. In the USA, between 1975 and 2016, ALL rates (ALLRs) rose 93.51\% from 1.91 to 3.70/100,000< 20 years. ALL is more common in Caucasian-Americans than amongst minorities. The cause of both the rise and the ethnic differential is unclear, however, prenatal cannabis exposure was previously linked with elevated childhood leukaemia rates. We investigated epidemiologically if cannabis use impacted nationally on ALLRs, its ethnic effects, and if the relationship was causal.
\end{abstract}

Methods: State data on overall, and ethnic ALLR from the Surveillance Epidemiology and End Results databank of the Centre for Disease Control (CDC) and National Cancer Institute (NCl) were combined with drug (cigarettes, alcoholism, cannabis, analgesics, cocaine) use data from the National Survey of Drug Use and Health; 74.1\% response rate. Income and ethnicity data was from the US Census bureau. Cannabinoid concentration was from the Drug Enforcement Agency Data. Data was analyzed in R by robust and spatiotemporal regression.

Results: In bivariate analyses a dose-response relationship was demonstrated between ALLR and Alcohol Use Disorder (AUD), cocaine and cannabis exposure, with the effect of cannabis being strongest ( $\beta$-estimate $=$ 3.33(95\%C.I. 1.97, 4.68), $\left.P=1.92 \times 10^{-6}\right)$. A strong effect of cannabis use quintile on ALLR was noted (Chi.Sq. $=$ $613.79, P=3.04 \times 10^{-70}$ ). In inverse probability weighted robust regression adjusted for other substances, income and ethnicity, cannabis was independently significant ( $\beta$-estimate $=4.75(0.48,9.02), P=0.0389)$. In a spatiotemporal model adjusted for all drugs, income, and ethnicity, cannabigerol exposure was significant ( $\beta$-estimate $=0.26(0.01$, $0.52), P=0.0444$ ), an effect increased by spatial lagging (THC: $\beta$-estimate $=0.47(0.12,0.82), P=0.0083)$. After missing data imputation ethnic cannabis exposure was significant $\left(\beta\right.$-estimate $\left.=0.64(0.55,0.72), P=3.1 \times 10^{-40}\right) .33 / 35$ minimum e-Values ranged from 1.25 to $3.94 \times 10^{36}$ indicative of a causal relationship. Relaxation of cannabis legal

\footnotetext{
* Correspondence: stuart.reece@bigpond.com

'Division of Psychiatry, University of Western Australia, Crawley, Western Australia 6009, Australia

${ }^{2}$ School of Medical and Health Sciences, Edith Cowan University, Joondalup,

Western Australia 6027, Australia
}

C C The Author(s). 2021 Open Access This article is licensed under a Creative Commons Attribution 4.0 International License, which permits use, sharing, adaptation, distribution and reproduction in any medium or format, as long as you give appropriate credit to the original author(s) and the source, provide a link to the Creative Commons licence, and indicate if changes were made. The images or other third party material in this article are included in the article's Creative Commons. licence, unless indicated otherwise in a credit line to the material. If material is not included in the article's Creative Commons licence and your intended use is not permitted by statutory regulation or exceeds the permitted use, you will need to obtain permission directly from the copyright holder. To view a copy of this licence, visit http://creativecommons.org/licenses/by/4.0/ The Creative Commons Public Domain Dedication waiver (http://creativecommons.org/publicdomain/zero/1.0/) applies to the data made available in this article, unless otherwise stated in a credit line to the data. 
paradigms had higher ALLR (Chi.Squ.Trend $=775.12, P=2.14 \times 10^{-112}$ ). Cannabis legal states had higher ALLR $\left(2.395 \pm 0.039\right.$ v. $\left.2.127 \pm 0.008 / 100,000, P=5.05 \times 10^{-10}\right)$.

Conclusions: Data show that ALLR is associated with cannabis consumption across space-time, is associated with the cannabinoids, THC, cannabigerol, cannabinol, cannabichromene, and cannabidiol, contributes to ethnic differentials, demonstrates prominent quintile effects, satisfies criteria for causality and is exacerbated by cannabis legalization.

Keywords: Acute lymphoid leukaemia, Childhood, Cannabis, Socioeconomic, Chromosomes, Genotoxicity, Epigenotoxicity

\section{Background}

Acute lymphoid leukaemia (ALL) is the commonest childhood cancer and accounts for about $25 \%$ of all childhood cancer cases [1]. In 2012 globally there were 352,000 cases of leukaemia with 265,000 deaths [2]. ALL has undergone a significant and unexplained increase in many nations, with global incidence and mortality rates of leukaemia of 4.7 and 3.4 / 100,000 closely aligned due its high mortality in developing nations [2]. Across Europe from 1978 to 1997 the ALL rate (ALLR) rose from 3.2 to 3.7 / 100,000 (16.9\%) in children, and from 0.85 to $1.2(44.7 \%)$ in adolescents, being markedly worse in the north [3]. In New Zealand from the period 1968-1972 to the period 1988-1990 the age standardized incidence of ALL rose from 4.83 to 7.04 / 100,000 (45.7\%) [4].

Marked ethnic disparities have also been reported in New Zealand with the rate in patients of Caucasian background being 3.2 / 100,000 compared to only 1.3 / 100,000 , or $40.6 \%$ less in those of Maori background. Similarly, in the USA long term data series from 1975 to 2017 show that the overall ALLR has risen markedly and is more prevalent in Americans of Caucasian background. Data on the Surveillance Epidemiology and End Results (SEER) Explorer website reveal that at the national level the age-adjusted ALLR for all ethnicities and all stages in ages < 20 years rose from 1.9124 / 100,000 in 1975 to $3.7007 / 100,000$ in 2016 , a $93.51 \%$ rise. The age-adjusted modelled ALLRs in patients $<20$ years rose from 2.50 to 3.45 (/100,000 or 37.4\%) 1975-2017 [5]. For the period 2000-2017 this is listed as a $0.6 \%$ annual percent change which is highly significant $(P<0.01)$. Nationally the mean rate in patients of Caucasian-American background is $3.75 \pm 0.76$ compared to $2.23 \pm 0.77$ (mean \pm S.E.M.) in patients of African-American background $(\mathrm{t}=14.42, \mathrm{df}=$ 53.14, $\left.P=2.60 \times 10^{-20}\right)[5]$.

The cause of this rise both in the USA and globally is unknown, as is the aetiology of the marked ethnic differences.

\section{Acute lymphoid leukaemia}

One clue may be the widespread recognition that most pediatric cancers arise during in utero life as a result of genetic or epigenetic errors [6, 7]. Amongst other factors reports exist of a link between prenatal cannabis exposure (PCE) and other leukaemia's, including acute myeloid leukaemia and acute myelomonocytic leukaemia $[8,9]$ although this association has been contested [10]. Accordingly, investigators have looked for a similar association with ALL with negative results [8-10], however outcomes may been confounded in earlier studies by ALL incidents requiring a threshold level of cannabis exposure. As cannabis use has risen globally since 1975, including use by pregnant women or females of reproductive age, the possibility of cannabis as a driver of these dual mysterious trends bears serious consideration.

National Survey of Drug Use and Health (NSDUH) data from the Substance Abuse and Mental Health Services Administration (SAMHSA) reveal that between 2016 and 2019 the number of Americans estimated to have used cannabis in the prior month rose in the three age categories 17-21 years, $18-25$ years and $>26$ years from 6.5 to $7.4 \%$, from 20.8 to $23.0 \%$ and from 7.2 to $10.2 \%$ respectively, representing total rises from 24 million to 31.5 million or $31.25 \%$ elevation across those three years [11]. In 2017 161,000 American women were estimated to have smoked cannabis while pregnant [11]. In a 2018 published study 69\% of Colorado dispensaries contacted advised pregnant women that cannabis use during pregnancy was safe [12], despite the American College of Obstetricians and Gynaecologists (ACOG) and the American Academy of Pediatrics (AAP) recommending otherwise [13-17]. 24\% of pregnant Californian teenagers recently tested positive to cannabis [18].

Whilst much of the debate relating to cannabis centres on its main psychoactive component tetrahydrocannabinol (THC), it is important to note that other cannabinoids have also been implicated in carcinogenic pathways. For example THC, cannabinol and cannabidiol have been implicated in end to end chromosomal translocations [19] and cannabidiol and is propyl ester cannabidivarin, in low micromolar doses, have been shown to induce DNA double strand breaks, induce micronucleus formation and directly oxidize both the purine and pyrimidine bases of DNA [20]. 
The present study examined if the previously described link between prenatal cannabis exposure and childhood leukaemia: (1) could be extended to ALL with different analytical strategies; (2) was observable and salient at the population health level; (3) linked in a space-time analysis with trends of cannabis use; (4) might be a driver of the recent rise in ALL; (5) might account for some of the variance related to the known and described ALLR by ethnic background; and (6) whether the relationship satisfied the quantitative formal criteria of causality. USA data was selected as both drug use and ALLRs by state and year, along with other important covariates, were publicly available.

\section{Methods}

Data

Age-adjusted ALLR for all patients $<20$ years and by selected ethnicities were downloaded via the SEERStat Software from the National Program of Cancer Registries (NPCR) and Surveillance Epidemiology and End Results (SEER) Incidence File from the US Cancer Statistics Public Use Database, Submission 2001-2017 [21]. National rates were taken from the SEER*Explorer website of the Centers for Disease Control Atlanta Georgia (CDC) and National Cancer Institute [5]. Drug use by US state was taken from the Restricted Use Data Analysis System (RDAS) of the Substance Abuse and Mental Health Data Archive (SAMHDA) of the National Survey of Drug Use and Health (NSDUH) from the Substance Abuse and Mental Health Services Administration (SAMHSA) for the period 2003-2017 [22]. The drugs of interest were monthly cigarette use (Cigarettes), Alcohol Use Disorder (AUD), last month cannabis use (Cannabis), last year analgesic misuse (Analgesics), and last year cocaine use (Cocaine). State median household income and ethnicity data was downloaded via the tidycensus package within $\mathrm{R}$ [23] from the US Census bureau. The ethnicities of interest were Caucasian-American, African-American, Asian-American, Hispanic-American, American Indian / Alaskan Native (AIAN)-American and Native Hawaiian-Pacific Islander (NHPI) - American. The THC concentration in Federal seizures was derived from publications from the Drug Enforcement Agency [24-26]. Data on the legal status of cannabis by state was taken from an internet search [27].

\section{Derived data}

The SAMHDA RDAS lists a variable at the national level called mrjmdays, which provides data on the intensity of cannabis use by ethnicity in the month prior to the survey in the categories 0 days, 1-2 days, 3-5 days, 6-19 days, 20-30 days. In each year of the NSDUH this variable can be summed by ethnicity so that the percentage using cannabis in each category can be summed to provide an index of the intensity of cannabis use at the Federal level for that ethnicity. These ethnic scores were then multiplied by the state rates of last month cannabis use and by the concentration of THC in Federal seizures to derive an estimate of ethnic THC exposure at the state level. State rates of cannabinoid exposure were derived by multiplying the concentration of the cannabinoid identified in Federal seizures by the mean rate of last month cannabis use in that state. Quintiles of cannabis use were calculated for each year by dividing states into five groups based on their surveyed last month cannabis use rates.

\section{Statistics}

Data was processed using $\mathrm{R}$ version 4.0.2 and R-Studio 1.3.1093 in October 2020 [28]. Data was pre-processed using the dplyr and tidycensus packages [23, 29]. Point estimates are listed as mean \pm standard error of the mean. Data were log-transformed guided by the Shapiro-Wilks test. Graphs were drawn in in R-Base, ggplot2 and lattice [28-30]. Maps were drawn in sf and ggplot2 [29, 31, 32]. Correlograms were drawn in corrplot and corrgram [33, 34]. Initial regression models were manually reduced in the classical manner by serial deletion of the least significant term to adduce final models. Two by two epidemiological table analysis was with epiR version 2.0.11 [35].

Several regression model forms were used in order to harness the various strengths of each model type. Straightforward linear regression was performed by linear regression. Mixed effects regression was used to capture the serial repeated nature of the data, to utilize inverse probability weights and to provide standard deviations for e-value calculations. Panel regression was performed as the data were inherently of that type, models could accept missing values, instrumental variables could be utilized, models could be temporally lagged and models could utilize inverse probability weights. However panel models do not accept data with repeated space-time indices as required in ethnicity studies and do not provide model standard deviations. Spatial regression was performed as data were inherently spatiotemporally distributed; spatial model coefficients confirmed the importance and significance of considering the spatiotemporal distribution of data; both spatial and temporal lagging could be conducted; and standard deviations could be calculated from which to calculate evalues; however inverse probability weights are not accepted, instrumental variables cannot be used and missing values are not tolerated. Robust regression was performed both to utilize inverse probability weights and to provide robust regression estimates, but standard deviations cannot be calculated from such models nor instrumental variables or lagging used. 
Linear regression was conducted in R-base. Fitted values were calculated from the model objects. Extension of the time series of linear models was performed using the predict function from package stats [28]. Robust regression was conducted with the survey package [36]. Repeated measures mixed effects regression was conducted with package nlme [37] using State as a random effect. Inverse probability weights were constructed using package ipw [38]. Panel regression was calculated using package plm [39]. E-Values were calculated using package EValue [40].

Spatial neighbour relationships were constructed in spdep [41] and spatiotemporal regression was conducted in splm [42] with the spatial panel random effects maximum likelihood (spreml) function [43]. Model specification and error structure was determined using the final model regression coefficients from a full model including serial correlation in the remainders, spatial error effects after Kelejian, Kapoor and Prucha [44], spatial lag effects and random effects (sem2srre) and only utilizing those effects which were significant as recommended [45].

Multiple imputation by chained equations for ethnicity data was conducted in R-package mice [46]. As 47.94\% of the state-level ethnicity data was missing 60 imputations with 60 iterations each were conducted following Van Buuren and Groothius-Oudshoorn [46, 47]. Imputation was performed by the classification tree ("cart") method which provided the best ethnic-specific ALLRs and resulted in fractions of missing data of only $3.1 \%$ in simple linear models regressing ALLR against cannabis exposure. All interactions were calculated prior to data imputation. Linear models were calculated on each imputed dataset and the pooled results were combined in accordance with Rubin's rules [46, 47].

All t-tests were two sided. $P<0.05$ was considered significant.

\section{Data sharing and availability}

Data including software code in $\mathrm{R}$ has been made freely available through the Mendeley data repository at this URL https://doi.org/10.17632/cf8c43yv62.1 .

\section{Ethics}

This study received ethical approval from the University of Western Australia Human Research Ethics Committee on 7 th January 2020 RA/4/20/7724.

\section{Results}

Data from the SEER*Explorer website reveal that the annual age-adjusted modelled incidence of pediatric ALL climbed significantly from 2.4970 to 3.4513 / 1,000,001,975-2017 across all races and all stages combined which represents an 0.7736 annual percent rise.
Amongst Caucasian-Americans the modelled ageadjusted rate rose from 2.6495 to $3.8150 / 100,000$ across this same period. No modelled rates are listed on the SEER*Explorer site for ethnic minorities. $50.89 \%$ of cases occurred in those younger than 20 years.

The NSDUH advises that it has a 74.1\% response rate [48].

Age-adjusted ALLRs by state were downloaded from the SEER database 2001-2017 as described. States with less than 15 cases are routinely suppressed. Complete datasets are required for spatiotemporal analysis as techniques do not accommodate missing data. Data from 31 states was complete. Data from Idaho, Mississippi and Nebraska was incomplete and was completed by temporal kriging. The missing data rate was 14 cases from 576 cases or $2.4 \%$. The complete kriged dataset is shown in Supplementary Table 1 with imputed data marked.

Figure 1 illustrates this data across the USA mapgraphically for log ALLR's.

Figure 2 shows the log rate of last month cannabis use map-graphically across the USA.

Figure 3 shows the ALLR as a function of the various substances used in the community. Rising trends are noted with AUD, cannabis, cocaine and median household income.

Figure 4 shows the ALLR as a function of exposure to the cannabinoids THC, cannabinol, cannabigerol, cannabichromene and cannabidiol.

Figure 5 shows the ALLR as a function of the ethnic THC exposure for all ethnicities (A) together and for (B) each of the ethnicities of interest.

Table 1 lists the various regression slopes of these lines together with their significance levels. The slope for the cannabis use line is noted to be highly significant $(\beta$-estimate $=3.33$, (95\%C.I. 1.97-4.68), $\left.P=1.92 \times 10^{-6}\right)$. The slopes of all of the regression lines for the cannabinoids cannabichromene, cannabigerol, cannabinol and cannabidiol were also significant. Log transformation improved the normality compliance of these data so these results are also listed.

Importantly the slopes of all of the lines for ethnic THC exposure were positive and significant with the single exception of the NHPI-American ethnicity.

Table 2 lists the correlation matrix for these data, conflated in both cases with the relevant significance matrix. The upper top right in both cases shows the Pearson correlation coefficients and the lower bottom left halfmatrix shows the applicable significance levels. Matrix A lists the various substances, income and ethnicities. Matrix B lists the results for ethnic THC exposure and cannabinoid exposure. Results are colour coded.

Similar results are listed graphically in the correlograms shown in Figs. 6 and 7 constructed with corrplot and corrgram respectively. 


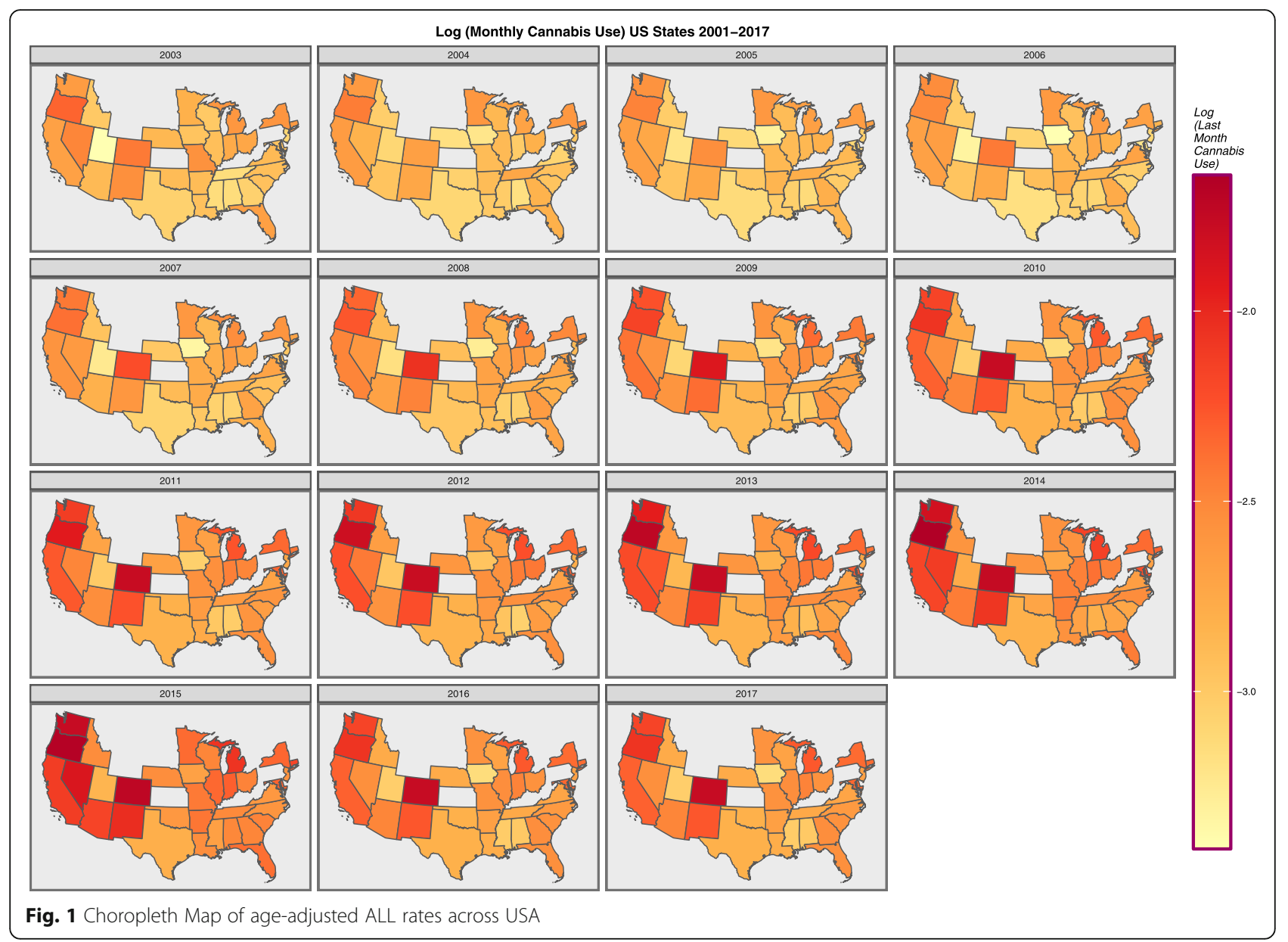

In Fig. 5 positive correlations are shown as red ellipses sloping upward and to the right. Stronger correlations are illustrated by narrower ellipses and the brighter tone shades. The positive association of the ALLR with substance and ethnic THC exposure is clear from these figures.

The corrgram correlogram shown in Fig. 7 has been ordered by hierarchical clustering for all covariates together. The ALLR is noted here to correlate with most cannabinoids, most ethnicities and most substances with the exception of cigarettes, NonHispanic Caucasian and Non-Hispanic AfricanAmerican ethnicities.

Table 3 shows the quintile composition by state for each quintile of cannabis use.

Figure 8 shows a quintile analysis of the cannabis use data $(\mathrm{A}, \mathrm{C})$ alongside the ALLR $(\mathrm{B}, \mathrm{D})$ by cannabis use quintile as both scatterplots $(B, D)$ over time and as boxplots over aggregated time $(\mathrm{A}, \mathrm{C})$. One reads the boxplots by noting where the notches do not overlap which signifies a statistically significant difference. The boxplots for ALL appear to broadly follow those for cannabis use. The applicable Chisquared test for trend for ALLRs by quintile is significant $($ Chi Squ. $=613.79, \mathrm{df}=112, P=3.04 \times$ $\left.10^{-70}\right)$.

Comparing the highest cannabis use quintile with the remainder 10,326 ALL cases were reported across all ages 2003-2017 in the highest cannabis use states from a total cumulative population of $367,557,212$ an overall rate of $2.8091 / 100,000$ compared to 60,645 from a cumulative population of $3,509,515,577$ in states in lower quintiles an overall rate of $1.7280 / 100,000$. These data equate to a risk ratio of 1.6256 , a risk difference of 1.0811 , an odds ratio (OR) of 1.6256 (95\%C.I. 1.52921, 1.6599), an attributable fraction amongst the exposed of $38.4857 \%$ (37.6910, 39.2972\%), and a population attributable fraction (PAF) of $0.0560 \quad(0.0548,0.0572), \quad P<<$ $10^{-320}$. However this is obviously an underestimate as populations in lower cannabis use quintiles were also exposed to rising rates of cannabinoid exposure overall: that is to say there was a "moving baseline". 

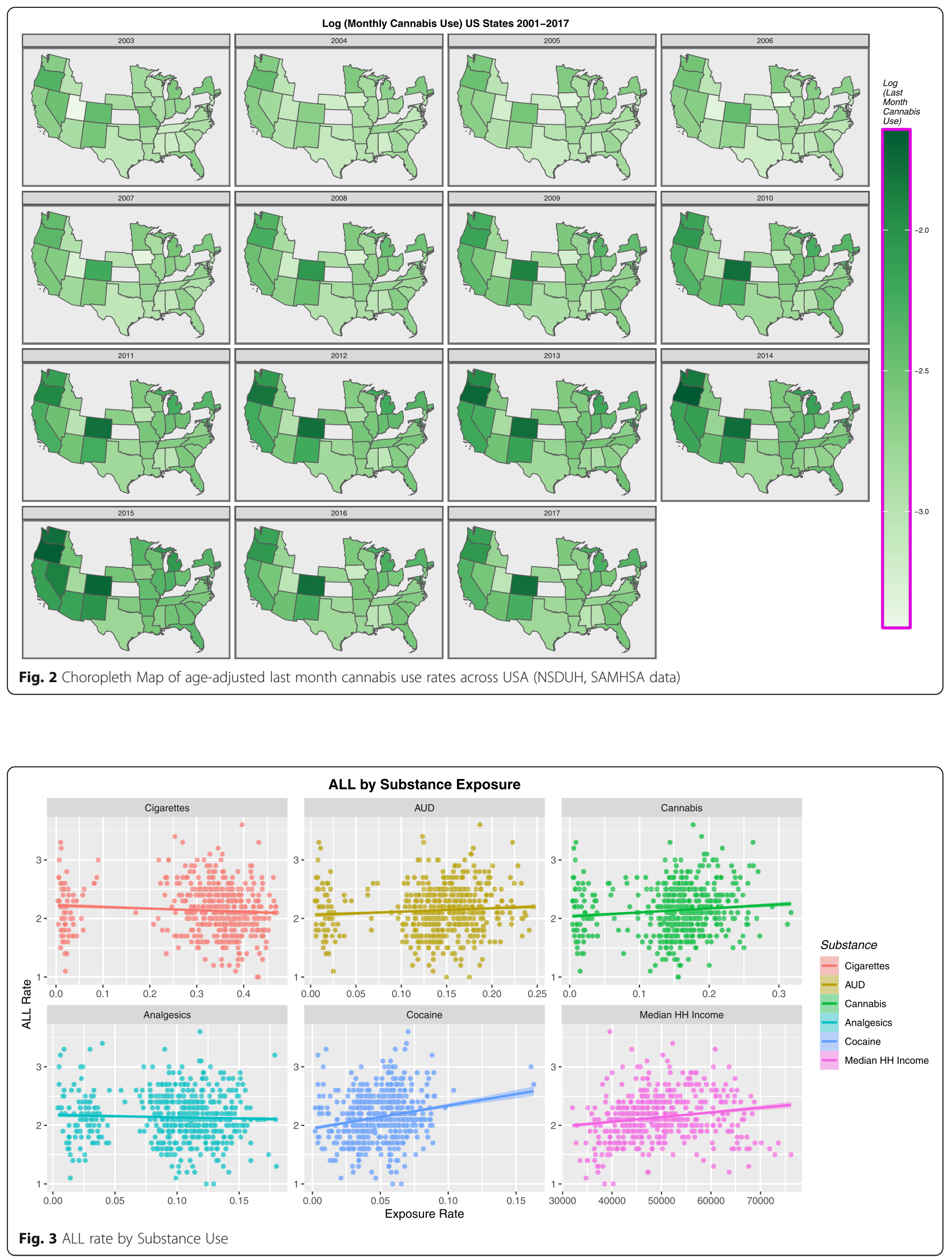


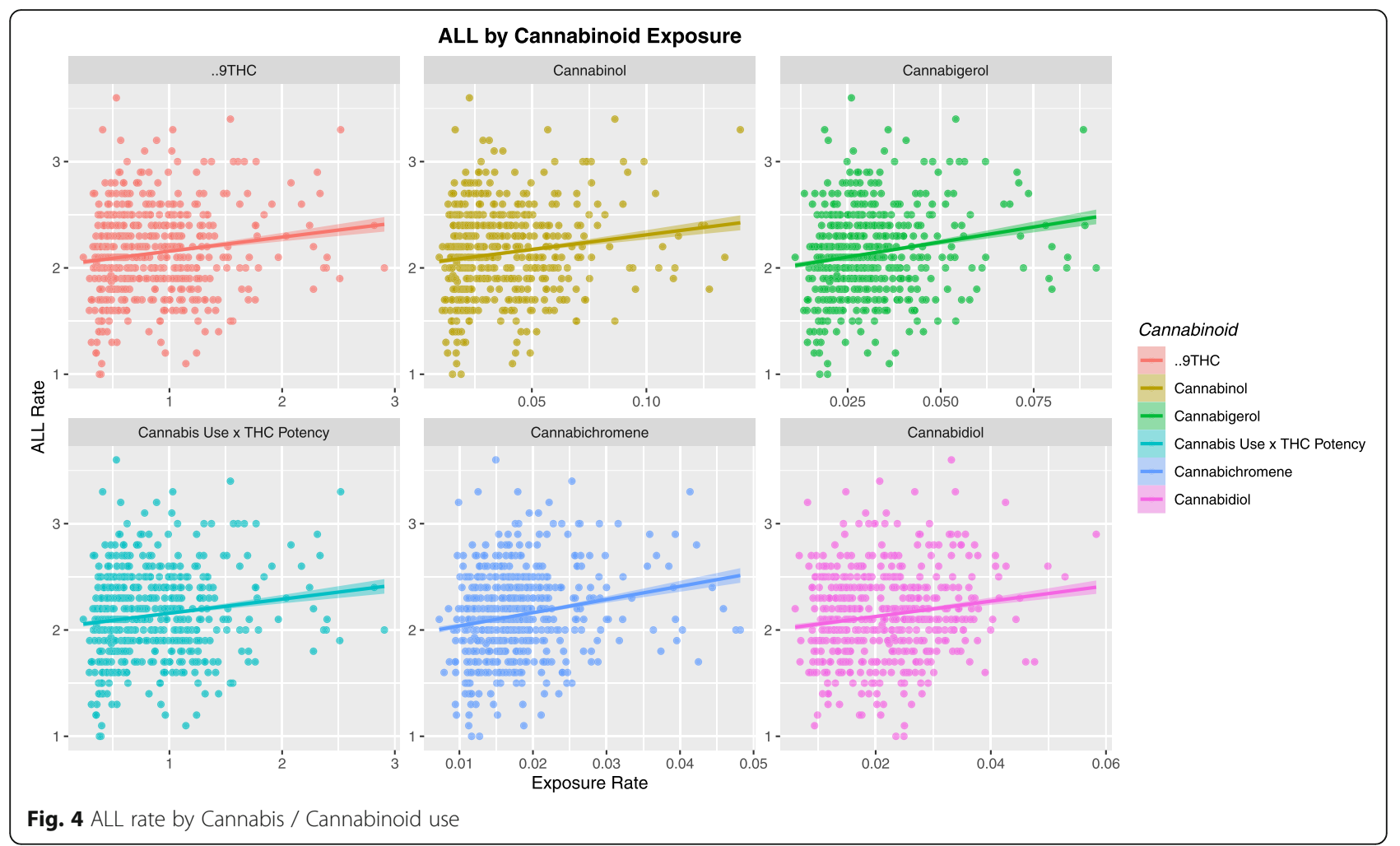

Table 4 lists some key introductory linear regressions of the ALLR against time, cannabis, substances and quintiles. Cannabis use quintiles have also been dichotomized as the upper two quintiles v. the lower three quintiles. In each case significant results are noted. The $\beta$ estimate coefficient for ALL regressed against cannabis use alone is $0.2967(0.1988-0.3945), P=4.25 \times 10^{-7}$.

Inverse probability weights can be calculated on this data for cannabis exposure as a function of other substance exposure.
Inverse probability weighted mixed effects models can be computed from this data with results shown in Table 5 . Cannabis use is shown to be highly and independently significant both alone and in additive models including all substances, income and all ethnicities. Terms including cannabis are also persistently significant in final interactive models.

Similar results are found at inverse probability weighted panel regression (Table 6). In additive and interactive models cannabis use is independently significant in models including all substances, income and
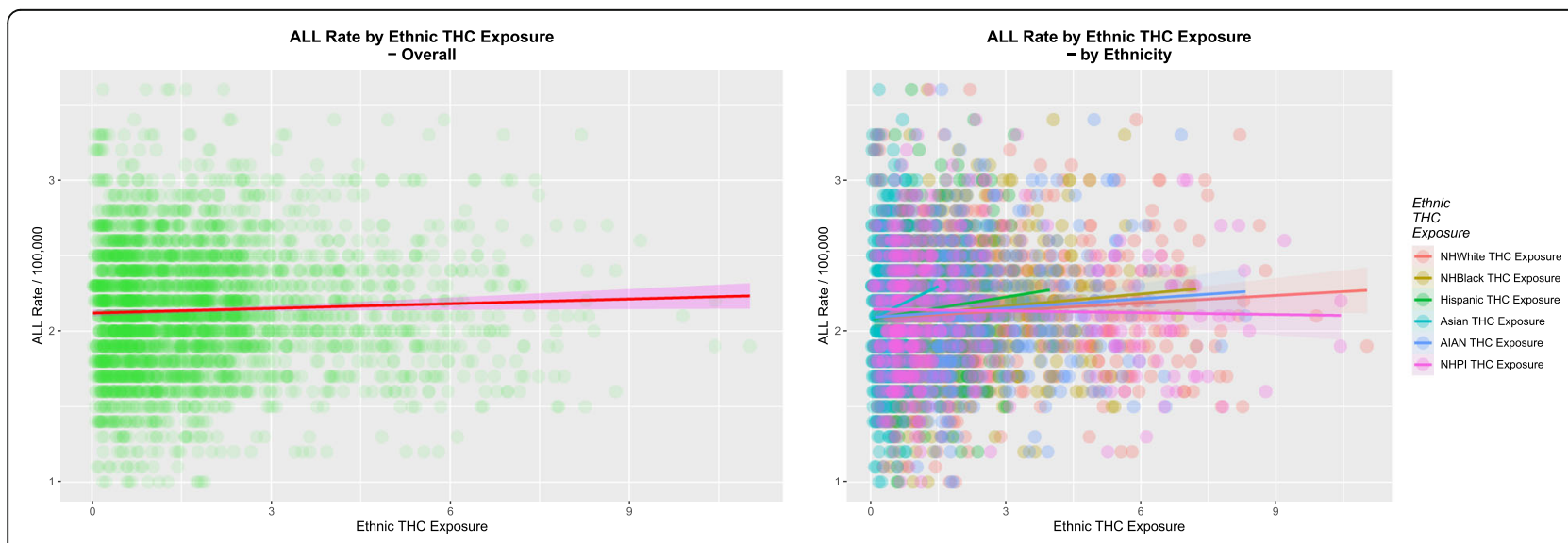

Fig. 5 ALL rate by Ethnic THC Exposure (A) Overall and (B) by Ethnicity 
Table 1 Introductory linear regression results

\begin{tabular}{|c|c|c|}
\hline \multirow[t]{2}{*}{ Parameter } & \multicolumn{2}{|l|}{ Parameter } \\
\hline & Estimate (C.I.) & $P$-Value \\
\hline \multicolumn{3}{|l|}{ Substances } \\
\hline Cannabis & $3.33(1.97,4.68)$ & $1.9 \mathrm{E}-06$ \\
\hline AUD & $4.32(1.9,6.75)$ & $5.2 \mathrm{E}-04$ \\
\hline Cocaine & $7.93(2.3,13.57)$ & 0.0060 \\
\hline Analgesics & $1.88(-1.93,5.7)$ & 0.3340 \\
\hline Cigarettes & $-2.78(-3.59,-1.96)$ & $5.6 \mathrm{E}-11$ \\
\hline \multicolumn{3}{|l|}{ Income } \\
\hline Income & $0.41(0.21,0.61)$ & $6.7 \mathrm{E}-05$ \\
\hline \multicolumn{3}{|l|}{ Cannabinoids } \\
\hline Cannabis & $3.33(1.97,4.68)$ & $1.9 \mathrm{E}-06$ \\
\hline CBC Exposure & $12.42(6.94,17.91)$ & 1.1. $\mathrm{E}-05$ \\
\hline CBG Exposure & $5.65(2.92,8.37)$ & $5.6 \mathrm{E}-05$ \\
\hline CBD Exposure & $7.19(3.1,11.29)$ & $6.2 \mathrm{E}-04$ \\
\hline CBN Exposure & $2.76(1.13,4.38)$ & $9.5 \mathrm{E}-04$ \\
\hline THC Exposure & $0.13(0.05,0.21)$ & 0.0012 \\
\hline \multicolumn{3}{|l|}{ Log (Cannabinoids) } \\
\hline $\log$ (Cannabis) & $0.3(0.18,0.41)$ & 4.3E-07 \\
\hline $\log (C B C$ Exposure) & $0.27(0.16,0.38)$ & $2.2 \mathrm{E}-06$ \\
\hline $\log ($ (CBG Exposure) & $0.22(0.12,0.31)$ & $1.0 \mathrm{E}-05$ \\
\hline $\log$ (THC Exposure) & $0.14(0.06,0.21)$ & 2.6E-04 \\
\hline $\log ($ CBN Exposure) & $0.12(0.05,0.19)$ & 4.3E-04 \\
\hline $\log (C B D$ Exposure) & $0.13(0.05,0.22)$ & 0.0023 \\
\hline \multicolumn{3}{|l|}{ Ethnicity } \\
\hline log (Hispanic-American) & $0.27(0.23,0.31)$ & $<2.2 \mathrm{E}-16$ \\
\hline $\log$ (Asian-American) & $0.17(0.12,0.22)$ & $2.0 \mathrm{E}-10$ \\
\hline log (NHPI-American) & $0.11(0.08,0.15)$ & $9.5 \mathrm{E}-10$ \\
\hline asinh (AIAN-American) & $3.45(1.86,5.04)$ & 2.6E-05 \\
\hline log (Caucasian-American) & $-0.33(-0.51,-0.14)$ & $5.1 \mathrm{E}-04$ \\
\hline log (Black-American) & $-0.16(-0.2,-0.13)$ & $<2.2 \mathrm{E}-16$ \\
\hline \multicolumn{3}{|l|}{ Ethnic THC Exposure } \\
\hline $\log$ (Asian THC Exposure) & $0.08(0.03,0.13)$ & 0.0025 \\
\hline log (Hispanic THC Exposure) & $0.08(0.03,0.13)$ & 0.0033 \\
\hline log (NHBlack THC Exposure) & $0.08(0.03,0.13)$ & 0.0033 \\
\hline log (NHWhite THC Exposure) & $0.08(0.03,0.14)$ & 0.0041 \\
\hline log (AIAN THC Exposure) & $0.07(0.01,0.13)$ & 0.0172 \\
\hline log (NHPI THC Exposure) & $0.02(-0.02,0.06)$ & 0.2810 \\
\hline
\end{tabular}

ethnicities (from $\beta$-estimate $=5.52 \quad(3.71-7.34), \quad P=$ $\left.4.71 \times 10^{-9}\right)$. When the cannabinoids cannabigerol and tetrahydrocannabinol (THC) are considered, cannabigerol is significant from $\beta$-estimate $=1.21(0.86,1.56)$, $\left.P=1.39 \times 10^{-11}\right)$.

However when ethnic exposure to THC is included in panel models as instrumental variables, the significance of the cannabis effect is greatly reduced ( $\beta$-estimate $=$ 0.117 (0.002, 0.232), $P=0.0462$ ).

Table 7 extends these panel regression results by presenting the results of models lagged to two, four, six and eight years. Highly significant results for terms including cannabis are noted at each time-lag.

Robust regression in inverse probability weighted marginal structural models was conducted on this data with results shown in Table 8. Interactive models for all substances, income and five ethnicities are shown. In both cases cannabis is significant both independently and in interaction with other substances.

Data on ALLRs by state was complete or almost complete for 34 states. In 14/576 cases missing data was completed by temporal kriging as described above. The states for which data was available are shown in the maps in Fig. 9 which illustrate the 2017 rates of (A) ALL and (B) cannabis use respectively.

Figure 10 presents the geospatial neighbourhood links (A) edited after derivation from the spdep::poly2nb function and (B) in final form.

The results of initial spatiotemporal models are shown in Table 9. Cannabis is again independently predictive of ALLR by itself and in additive models with other substances. In a full interactive model with cannabinoids and other substances, income and ethnicities, cannabigerol remains independently significant in the final model.

As cannabigerol was the most powerful term in these spatial models, lagged models were explored where cannabigerol was lagged spatially and temporally. These results are presented in Table 10. Once again terms including $\mathrm{THC}$ and cannabigerol are significant and THC and cannabigerol are both independently significant with positive coefficients.

Table 11 explores the effects of ethnic THC exposure in more detail in three models, additive for ethnic THC exposure, interactive for ethnic THC exposure, and interactive for various substances and interactive for ethnic THC exposure together. In all cases ethnic THC exposure is significant with positive coefficients.

Figure 11 (A) shows the intensity of last month cannabis use for Caucasian-American and AfricanAmerican ethnicities. Fig. 11 (B) shows the SEER dataset for the ALLRs by these two ethnicities. Fig. 11 (C) projects this data out over the whole time period 1975- 
Table 2 Correlation \& significance matrices

Correlation \& Significance Matrices - Drugs and Ethnicity

\begin{tabular}{|c|c|c|c|c|c|c|c|c|c|c|c|c|c|}
\hline & Rate & Cigarettes & AUD & Cannabis & Analgesics & Cocaine & MH_Income & $\begin{array}{l}\text { Caucasian- } \\
\text { American }\end{array}$ & $\begin{array}{c}\text { African- } \\
\text { American }\end{array}$ & $\begin{array}{c}\text { Asian- } \\
\text { American }\end{array}$ & $\begin{array}{c}\text { AIAN- } \\
\text { American }\end{array}$ & $\begin{array}{l}\text { Hispanic- } \\
\text { American } \\
\end{array}$ & $\begin{array}{c}\text { NHPI- } \\
\text { American }\end{array}$ \\
\hline Rate & 1 & -0.2849 & 0.1531 & 0.2090 & 0.0429 & 0.1215 & 0.1470 & -0.1149 & -0.4614 & 0.2857 & 0.1852 & 0.5068 & 0.2161 \\
\hline $\begin{array}{l}\text { Cigare } \\
\text { C. }\end{array}$ & $57 \mathrm{E}-1$ & & 0.3374 & -0.3547 & 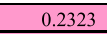 & -0.0006 & -0.7216 & 0.0965 & 0.2292 & -0.5305 & 0.1216 & -0.4166 & -0.3889 \\
\hline AUD & $2 \mathrm{E}-04$ & $4.79 \mathrm{E}-15$ & 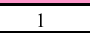 & 0.0205 & & 3760 & -0.1286 & .0356 & -0.4370 & 70 & 0.2134 & 1275 & -0.0900 \\
\hline $\begin{array}{ll}\text { Canna } \\
\end{array}$ & $92 \mathrm{E}-06$ & & $45 \mathrm{E}-01$ & & 0.2215 & 0.2183 & & 0.0095 & -0.2155 & 457 & 0.0447 & 2782 & .1834 \\
\hline Analgesi & $34 \mathrm{E}-01$ & $1.13 \mathrm{E}-07$ & $8.90 \mathrm{E}-05$ & $36 \mathrm{E}-07$ & 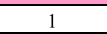 & 0.1884 & -0.2669 & -0.0758 & -0.1358 & -0.0482 & 0.2865 & .0909 & .3507 \\
\hline Cocaine & & $9.90 \mathrm{E}-01$ & & & $85 \mathrm{E}-05$ & 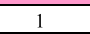 & 0.0596 & & & & & 004 & 0.0047 \\
\hline Income & $9 \mathrm{E}-04$ & $3.63 \mathrm{E}-83$ & $3.64 \mathrm{E}-03$ & $2.05 \mathrm{E}-19$ & $0 \mathrm{E}-10$ & $79 \mathrm{E}-01$ & & 0.1144 & -0.2349 & 5749 & -0.2071 & 1493 & 0.2246 \\
\hline Cauc & & & & & & & & 1 & -0.3327 & & & 573 & .0189 \\
\hline African-American & -28 & & & 9. & -03 & & & $21 \mathrm{E}-14$ & & -0.1123 & -0.3506 & 778 & 0.4026 \\
\hline Asian- $\mathrm{A}$ & $0 \mathrm{E}-11$ & $2.34 \mathrm{E}-38$ & 2.8 & 9.2 & & & & $2.82 \mathrm{E}-22$ & & 1 & -0.1552 & 0.4469 & 0.3303 \\
\hline AIAN-A & & & & & & & & $2.77 \mathrm{E}-07$ & & & 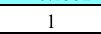 & 0.4159 & 0.0794 \\
\hline Hispanic-America & $1.23 \mathrm{E}-34$ & $7.82 \mathrm{E}-23$ & $3.94 \mathrm{E}-03$ & $1.61 \mathrm{E}-10$ & $4.02 \mathrm{E}-02$ & $4.34 \mathrm{E}-17$ & $7.20 \mathrm{E}-04$ & $2.12 \mathrm{E}-64$ & $8.90 \mathrm{E}-18$ & $2.09 \mathrm{E}-26$ & $9.42 \mathrm{E}-23$ & 1 & 0.2477 \\
\hline NHPI-American & $8.32 \mathrm{E}-07$ & $7.38 \mathrm{E}-20$ & $4.22 \mathrm{E}-02$ & $3.09 \mathrm{E}-05$ & $3.33 \mathrm{E}-16$ & $9.15 \mathrm{E}-01$ & $2.97 \mathrm{E}-07$ & $6.70 \mathrm{E}-01$ & $2.69 \mathrm{E}-21$ & $1.89 \mathrm{E}-14$ & $7.31 \mathrm{E}-02$ & $1.43 \mathrm{E}-08$ & \\
\hline
\end{tabular}

Correlation \& Significance Matrices - Cannabinoids and Ethnic THC Exposure

\begin{tabular}{|c|c|c|c|c|c|c|c|c|c|c|c|c|c|}
\hline & $\begin{array}{l}\text { ALL } \\
\text { Rate }\end{array}$ & $\begin{array}{c}\text { NHCaucasian } \\
\text { THC } \\
\text { Exposure }\end{array}$ & $\begin{array}{c}\text { NHAfrican } \\
\text { THC } \\
\text { Exposure }\end{array}$ & $\begin{array}{c}\text { Hispanic } \\
\text { THC } \\
\text { Exposure }\end{array}$ & $\begin{array}{c}\text { Asian } \\
\text { THC } \\
\text { Exposure }\end{array}$ & $\begin{array}{c}\text { AIAN } \\
\text { THC } \\
\text { Exposure }\end{array}$ & $\begin{array}{c}\text { NHPI } \\
\text { THC } \\
\text { Exposure }\end{array}$ & $\begin{array}{c}\text { THC } \\
\text { Exposure }\end{array}$ & $\begin{array}{c}\text { CBD } \\
\text { Exposure }\end{array}$ & $\begin{array}{c}\mathrm{CBC} \\
\text { Exposure }\end{array}$ & $\begin{array}{c}\text { CBN } \\
\text { Exposure }\end{array}$ & $\begin{array}{c}\text { CBG } \\
\text { Exposure }\end{array}$ & $\begin{array}{c}\text { Monthly } \\
\text { Cannabis } \\
\text { Use x } \\
\text { THC } \\
\text { Potency }\end{array}$ \\
\hline ALL Rate & 1 & 0.1036 & 0.1063 & 0.1084 & 0.1127 & 0.0889 & 0.0240 & 0.1426 & 0.1510 & 0.1932 & 0.1459 & 0.1775 & 0.1426 \\
\hline Cauc-Am. THC Exposure & 0.0192 & 1 & 0.9938 & 0.9946 & 0.9668 & 0.9740 & 0.7784 & 0.9771 & -0.3019 & 0.8143 & 0.9371 & 0.9258 & 0.9771 \\
\hline Afric-Am. THC Exposure & 0.0163 & $0.00 \mathrm{E}+00$ & 1 & 0.9840 & 0.9699 & 0.9736 & 0.7554 & 0.9668 & -0.2972 & 0.7944 & 0.9424 & 0.9207 & 0.9668 \\
\hline Hisp.-Am. THC Exposure & 0.0143 & $0.00 \mathrm{E}+00$ & $0.00 \mathrm{E}+00$ & 1 & 0.9649 & 0.9623 & 0.7370 & 0.9727 & -0.3192 & 0.8081 & 0.9294 & 0.9140 & 0.9727 \\
\hline Asian-Am. THC Exposure & 0.0108 & $3.13 \mathrm{E}-303$ & $\begin{array}{l}1.033152 \mathrm{e}- \\
313\end{array}$ & $\begin{array}{r}2.97 \mathrm{E}- \\
297\end{array}$ & 1 & 0.9230 & 0.6854 & 0.9424 & -0.3023 & 0.7643 & 0.8940 & 0.8856 & 0.9424 \\
\hline NHPI-Am. THC Exposure & 0.5879 & $8.49 \mathrm{E}-105$ & $2.52 \mathrm{E}-95$ & $1.83 \mathrm{E}-88$ & $5.45 \mathrm{E}-72$ & $1.07 \mathrm{E}-87$ & 1 & 0.7699 & -0.3312 & 0.6379 & 0.7502 & 0.7324 & 0.7699 \\
\hline THC Exposure & 0.0012 & $0.00 \mathrm{E}+00$ & $3.02 \mathrm{E}-303$ & $0.00 \mathrm{E}+00$ & $\begin{array}{r}8.84 \mathrm{E}- \\
244 \\
\end{array}$ & $\begin{array}{r}1.91 \mathrm{E}- \\
215 \\
\end{array}$ & $\begin{array}{r}3.63 \mathrm{E}- \\
101 \\
\end{array}$ & 1 & -0.1611 & 0.9002 & 0.9488 & 0.9725 & 1.0000 \\
\hline Cannabidiol Exposure & 0.0006 & $3.32 \mathrm{E}-12$ & $7.40 \mathrm{E}-12$ & $1.52 \mathrm{E}-13$ & $3.09 \mathrm{E}-12$ & $1.52 \mathrm{E}-10$ & $1.61 \mathrm{E}-14$ & $2.59 \mathrm{E}-04$ & 1 & 0.2175 & -0.1790 & 0.0271 & -0.1611 \\
\hline Cannabichromene Exposure & $1.12 \mathrm{E}-05$ & 4.45E-122 & $4.29 \mathrm{E}-112$ & $\begin{array}{r}7.20 \mathrm{E}- \\
119 \\
\end{array}$ & 7.44E-99 & $\begin{array}{r}1.67 \mathrm{E}- \\
100 \\
\end{array}$ & $1.33 \mathrm{E}-59$ & $1.45 \mathrm{E}-185$ & $7.04 \mathrm{E}-07$ & 1 & 0.8330 & 0.9403 & 0.9002 \\
\hline Cannabinol Exposure & 0.0010 & $2.50 \mathrm{E}-234$ & $8.18 \mathrm{E}-244$ & $\begin{array}{r}4.22 \mathrm{E}- \\
222 \\
\end{array}$ & $\begin{array}{r}3.11 \mathrm{E}- \\
179 \\
\end{array}$ & $\begin{array}{r}7.03 \mathrm{E}- \\
201 \\
\end{array}$ & $2.49 \mathrm{E}-93$ & $2.38 \mathrm{E}-256$ & $4.80 \mathrm{E}-05$ & $\begin{array}{r}1.08 \mathrm{E}- \\
132 \\
\end{array}$ & 1 & 0.9379 & 0.9488 \\
\hline Cannabigerol Exposure & $5.57 \mathrm{E}-05$ & $8.66 \mathrm{E}-217$ & $9.78 \mathrm{E}-210$ & $\begin{array}{r}3.52 \mathrm{E}- \\
201\end{array}$ & $\begin{array}{r}2.76 \mathrm{E}- \\
171\end{array}$ & $\begin{array}{r}9.28 \mathrm{E}- \\
176 \\
\end{array}$ & $7.61 \mathrm{E}-87$ & $\begin{array}{l}1.976263 \mathrm{e}- \\
323\end{array}$ & $5.41 \mathrm{E}-01$ & $\begin{array}{r}7.38 \mathrm{E}- \\
240 \\
\end{array}$ & $\begin{array}{r}8.80 \mathrm{E}- \\
236 \\
\end{array}$ & 1 & 0.9725 \\
\hline
\end{tabular}

\section{A CorrPlot - Drug \& Ethnic Correlation Matrix of ALL Rate}

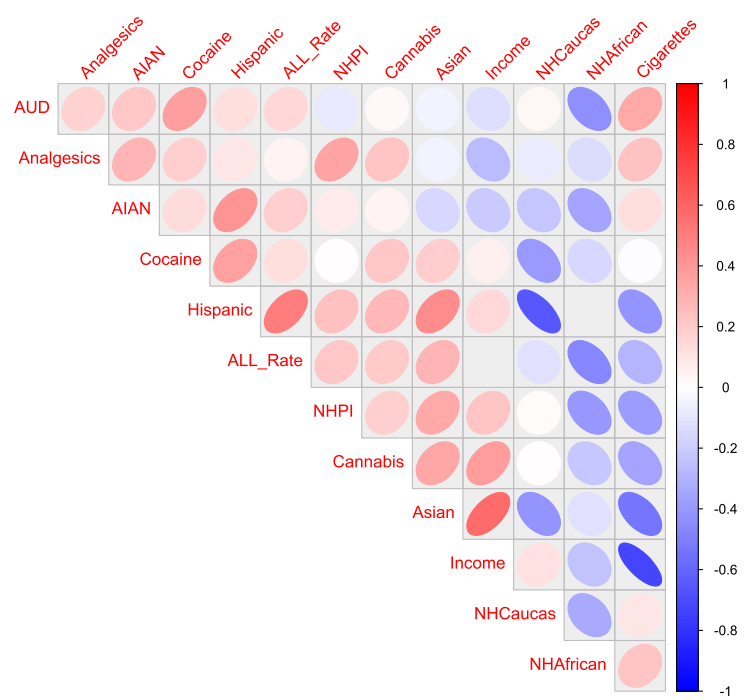

\section{B Corrgram - Correlation Matrix ALL Cannabinoid \& Ethnic Covariates}

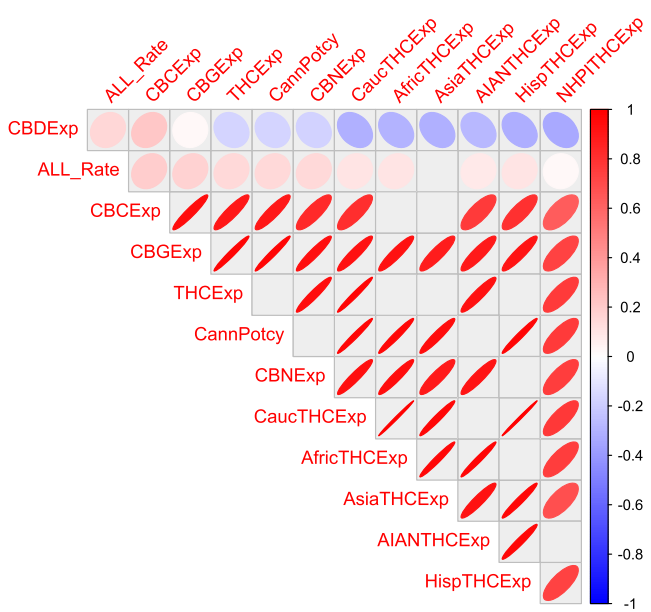

Fig. 6 Corrplot correlogram (A) Drugs and ethnic correlations and (B) Cannabinoid and Ethnic THC Exposure correlations 


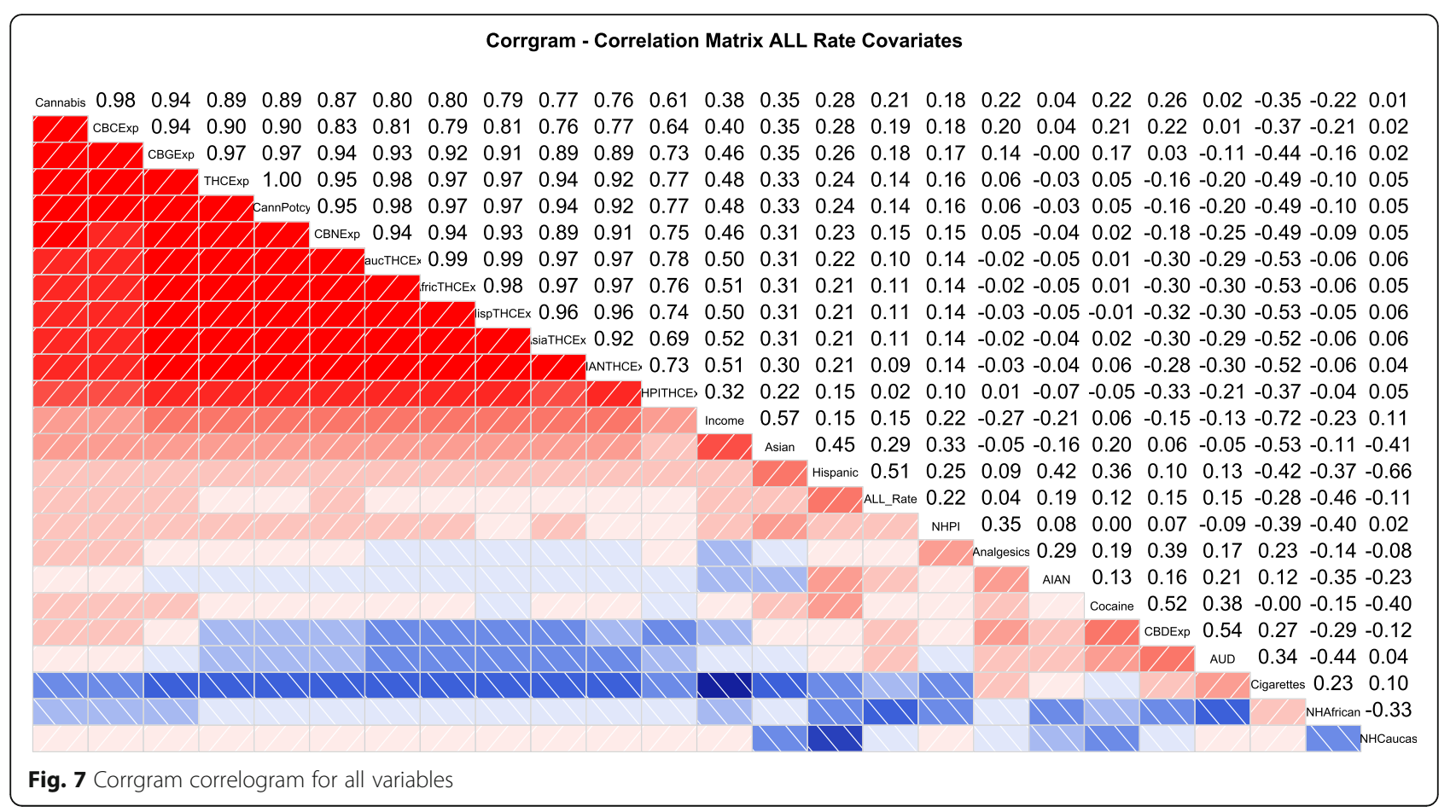

2017 based on extensions of the linear models. The mean state ethnicity ALLRs are $3.47 \pm 0.13$ and $2.47 \pm 0.27$ (mean \pm S.E.M., /100,000) for CaucasianAmerican and African-Americans respectively $(\mathrm{t}=24.03$, df $=101.72, P=4.91 \times 10^{-44}$ )

These interesting and provocative ethnic differences between the Caucasian-American and the AfricanAmerican populations invited further exploration. However 489 of the of the 1020 (47.94\%) datapoints were missing or suppressed. These were imputed by the multiple imputation by chained equations routine in $\mathrm{R}$ package mice. Following [46, 47] 60 imputations each with 60 iterations were employed due to the large amount of missing data.

Figure 12 shows successful convergence of the imputations as stripplots with successively increasing imputations and iterations.

Figure 13 shows the density plot of the imputed data. Imputed data are shifted relative to the main dataset as the imputations occurred primarily in the ethnic minorities which had a lower mean ALLR.

Table 12 presents the results of linear regression on the imputed datasets. The ALLR is noted to be highly significantly related to ethnic THC exposure alone ( $\beta$-estimate $\left.=0.14(0.12,0.17), P=3.4 \times 10^{-26}\right)$, and ethnic THC exposure is independently highly predictive in an additive $\left(\beta\right.$-estimate $\left.=0.53(0.44,0.61), P=6.2 \times 10^{-31}\right)$ and an interactive $(\beta$-estimate $=0.42(0.35,0.50), P=$
$1.7 \times 10^{-27}$ ) model. When cannabinoids are included as primary covariates, ethnic THC exposure remains significant in interactive terms. Indeed ethnic THC exposure remains significant in this table as model complexity increases.

Table 13 collates some of the e-Values calculated from the above analyses. The minimum e-Values are listed in descending order in Table 14. 33 / 35 e-Values are > 1.25 which is the cut-off quoted as indicative of causal effects in the literature [49]. The highest minimum eValue relates to ethnic cannabis exposure differences by ethnicity $\left(3.94 \times 10^{36}\right)$.

Having demonstrated prominent dose-response and quintile effects, the effects of cannabis legalization remain to be considered. Cannabis legalization is associated with higher rates of use, higher intensity of use and higher concentration of THC in cannabis products [50]. The rates of cannabis use $(A, C)$ and ALL $(B, D)$ by legal status are shown in Fig. 14 both as scatterplots $(C, D)$ and boxplots (A, B). The scatterplots and boxplots for ALL appear to track those for cannabis use. The mean ALLR under illegal, decriminalized, medical and legal paradigms were $2.091 \pm 0.009,2.077 \pm 0.014,2.305 \pm 0.018$ and $2.395 \pm 0.039 / 100,000$ (mean \pm S.E.M.) respectively. The Chi squared test for trend is highly significant (Chi Squ. $=775.12, \mathrm{df}=84, P=2.14 \times 10^{-112}$ ).

Data may be dichotomized as the legal paradigm $\mathrm{v}$. the others as shown in Fig. 15. The notches of the ALL 
Table 3 Cannabis use Quintiles by State

\begin{tabular}{|c|c|c|c|c|c|}
\hline State & Quintile 1 & Quintile 2 & Quintile 3 & Quintile 4 & Quintile 5 \\
\hline Alabama & 14 & 1 & 0 & 0 & 0 \\
\hline Arizona & 0 & 3 & 7 & 5 & 0 \\
\hline Arkansas & 0 & 6 & 9 & 0 & 0 \\
\hline California & 0 & 0 & 0 & 15 & 0 \\
\hline Colorado & 0 & 0 & 0 & 1 & 14 \\
\hline Connecticut & 0 & 0 & 2 & 12 & 1 \\
\hline Florida & 0 & 0 & 14 & 1 & 0 \\
\hline Georgia & 2 & 3 & 8 & 2 & 0 \\
\hline Idaho & 6 & 9 & 0 & 0 & 0 \\
\hline Illinois & 0 & 2 & 13 & 0 & 0 \\
\hline Indiana & 0 & 1 & 2 & 12 & 0 \\
\hline lowa & 14 & 1 & 0 & 0 & 0 \\
\hline Louisiana & 7 & 8 & 0 & 0 & 0 \\
\hline Maryland & 2 & 3 & 1 & 9 & 0 \\
\hline Michigan & 0 & 0 & 0 & 15 & 0 \\
\hline Minnesota & 0 & 3 & 7 & 4 & 1 \\
\hline Mississippi & 14 & 1 & 0 & 0 & 0 \\
\hline Missouri & 0 & 0 & 14 & 1 & 0 \\
\hline Nebraska & 9 & 4 & 2 & 0 & 0 \\
\hline Nevada & 0 & 0 & 4 & 9 & 2 \\
\hline New Jersey & 8 & 7 & 0 & 0 & 0 \\
\hline New Mexico & 0 & 0 & 0 & 15 & 0 \\
\hline New York & 0 & 0 & 0 & 15 & 0 \\
\hline North Carolina & 0 & 11 & 4 & 0 & 0 \\
\hline Ohio & 0 & 0 & 13 & 2 & 0 \\
\hline Oklahoma & 10 & 4 & 1 & 0 & 0 \\
\hline Oregon & 0 & 0 & 0 & 0 & 15 \\
\hline South Carolina & 4 & 6 & 5 & 0 & 0 \\
\hline Tennessee & 1 & 8 & 4 & 2 & 0 \\
\hline Texas & 15 & 0 & 0 & 0 & 0 \\
\hline Utah & 15 & 0 & 0 & 0 & 0 \\
\hline Virginia & 2 & 8 & 4 & 1 & 0 \\
\hline Washington & 0 & 0 & 0 & 2 & 13 \\
\hline Wisconsin & 0 & 14 & 1 & 0 & 0 \\
\hline
\end{tabular}

boxplots in the two groups are noted to clearly not overlap. The mean ALLR in the legal and not-legal groups were $2.395 \pm 0.039$ and $2.127 \pm 0.008 / 100,000$ respectively $\left(\mathrm{t}=6.7151, \mathrm{df}=128.16, P=5.05 \times 10^{-10}\right)$.

When these data are analyzed by linear regression the highly significant results shown in Table 15 are found. These results are associated with minimum e-Values mostly $>1.90$ as shown in the upper part of Table 13 . $33 / 35$ e-Values are $>1.25$ which is the cut-off point described in the literature for causal effects 1.25 [49]. 12 e-Values are $>100$.

\section{Discussion}

Main results

This study significantly extends prior cohort analyses linking cannabis use with the incidence of childhood leukaemia. We here report a positive relationship between cannabis exposure and ALLR for the first time. 


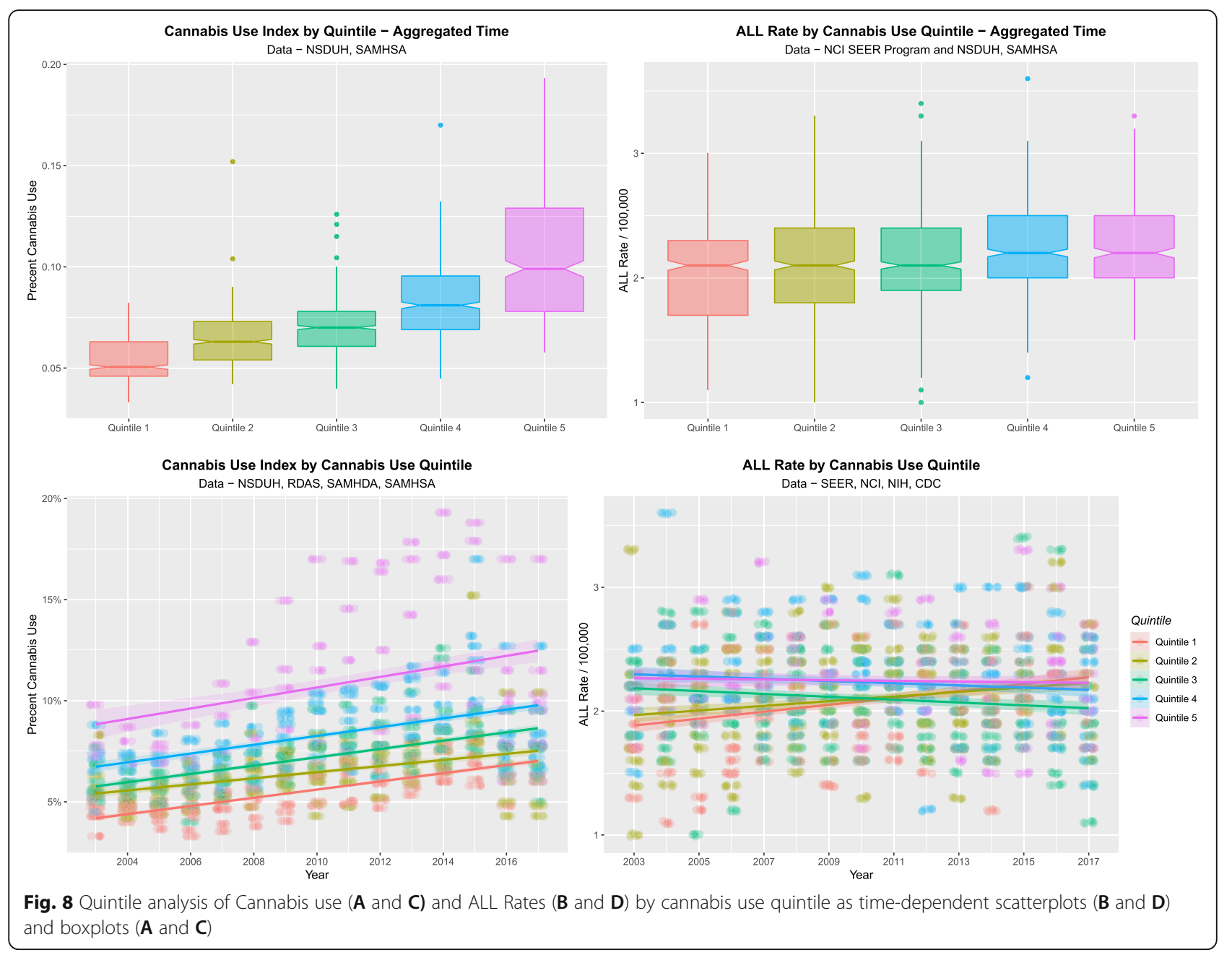

Importantly data analysis shows that this result is not limited to a single cohort analysis, but is generalizable across the pediatric cancer epidemiology of a whole nation for the most common malignant disease of childhood. Further data indicate that ethnic differences in ALL incidence are associated in part with differing intensity of cannabis use, suggesting a gene-environment interaction. The present report includes other substances, median household income and ethnicity and finds that the effects of exposure to cannabis and cannabinoids is independently significant and persistent in final robust regression models. In bivariate analysis the ALLR was related to AUD, cannabis use and estimates of state-level cannabinoid exposure to THC, cannabinol, cannabigerol, cannabichromene and cannabidiol and strong dose-response effects were demonstrated. Similarly the effect of ethnic THC exposure is maintained across most ethnicities. Inclusion of ethnic THC exposure as either a primary covariate or an instrumental variable greatly mollifies the effect of cannabis exposure per se. The cannabis-ALL link was strongly maintained when analyzed across space and time. The causal nature of the relationship was demonstrated by significant results upon inclusion of inverse probability weights in mixed effects, panel, and robust regression models, and by the demonstration that $33 / 35$ minimum e-Values were above the cut-off threshold of 1.25 extending up to $3.94 \times 10^{36}$. Consistent with the general dose-response effects prominent quintile effects were demonstrated, as were major effects of cannabis legalization which has been linked with increased cannabis availability, use, intensity of use and THC potency [50].

The present study reports a strong, robust, spatiotemporal and causal link between cannabis use and ALLR. Current findings contrast with cohort and case-control studies undertaken two to three decades ago investigating the association between ALL and cannabis where no apparent association was identified [8-10]. However, 
Table 4 Linear regression models

\begin{tabular}{|c|c|c|c|c|c|c|c|}
\hline \multirow[t]{2}{*}{ Parameter } & \multicolumn{2}{|l|}{ Parameter } & \multicolumn{5}{|c|}{ Model Parameters } \\
\hline & Estimate (C.I.) & $P$-Value & SD & R-Squared & $\mathrm{F}$ & $\mathrm{dF}$ & $\mathbf{P}$ \\
\hline \multicolumn{8}{|c|}{ Im (ALL_Rate Cannabis) } \\
\hline Cannabis & $0.3(0.18,0.41)$ & 4.3E-07 & 4.06E-01 & 0.4728 & 26.26 & 1508 & $4.2 \mathrm{E}-07$ \\
\hline \multicolumn{8}{|l|}{ Im (ALL_Rate Time) } \\
\hline Year & $0.01(0,0.01)$ & 0.1670 & 4.06E-01 & 0.0018 & 1.916 & 1508 & 0.1670 \\
\hline \multicolumn{8}{|c|}{ Im (ALL_Rate $\sim$ Time ${ }^{*}$ Cannabis) } \\
\hline Year & $0.04(-0.18,-0.02)$ & 0.0130 & 0.4039 & 0.05638 & 11.14 & 3506 & 4.3E-07 \\
\hline Cannabis & $30.51(13.22,132.81)$ & 0.0171 & & & & & \\
\hline Year: Cannabis & $-0.02(-0.07,-0.01)$ & 0.0176 & & & & & \\
\hline \multicolumn{8}{|l|}{ Additive model } \\
\hline \multicolumn{8}{|c|}{ Im (ALL_Rate $\sim$ Cigarettes + AUD + Cannabis + Analgesics + Cocaine $)$} \\
\hline cigmon & $-3.3(-4.19,-2.41)$ & $1.3 \mathrm{E}-12$ & 0.382 & 0.1561 & 32.38 & 3506 & $<2.2 \mathrm{E}-16$ \\
\hline AUD & $7.58(5.17,9.99)$ & $1.5 \mathrm{E}-09$ & & & & & \\
\hline Cannabis & $0.14(0.03,0.26)$ & 0.0154 & & & & & \\
\hline \multicolumn{8}{|l|}{ Quintiles } \\
\hline \multicolumn{8}{|c|}{ Im (ALL_Rate Quintile) } \\
\hline Quintile 4 & $0.18(0.07,0.29)$ & 0.0020 & 0.4071 & 0.0234 & 4.047 & 4505 & 0.0031 \\
\hline Quintile 5 & $0.19(0.06,0.32)$ & 0.0037 & & & & & \\
\hline \multicolumn{8}{|c|}{ Im (ALL_Rate Year * Quintile) } \\
\hline Year & $0.03(0.01,0.05)$ & 0.0061 & 0.4071 & 0.0416 & 3.456 & 9500 & 0.0004 \\
\hline Quintile 3 & $79.2(26.91,131.49)$ & 0.0031 & & & & & \\
\hline Quintile 4 & $74.23(21.02,127.44)$ & 0.0065 & & & & & \\
\hline Quintile 5 & $61.55(3.2,119.9)$ & 0.0392 & & & & & \\
\hline Year: Quintile 3 & $-0.04(-0.07,-0.01)$ & 0.0032 & & & & & \\
\hline Year: Quintile 4 & $-0.04(-0.06,-0.01)$ & 0.0066 & & & & & \\
\hline Year: Quintile 5 & $-0.03(-0.06,0)$ & 0.0397 & & & & & \\
\hline \multicolumn{8}{|c|}{ Im (ALL_Rate Year * Quintiles_Dichotomized) } \\
\hline Upper Quintiles & $0.15(0.07,0.22)$ & 0.0001 & 0.4102 & 0.0272 & 15.24 & 1508 & 0.0001 \\
\hline
\end{tabular}

numerous in vitro studies investigating genotoxic changes associated with cannabinoid exposure have reported that a threshold exposure is required before detrimental changes occur. It is therefore possible that the apparent disparity in findings are explained by increasing frequency of cannabis use, especially amongst existing users, and increased concentration in cannabis products of THC and many other genotoxic cannabinoids over the last two decades [24-26] resulting in a general movement of the whole population into a much higher risk category.

The potential impact of this investigation is far reaching given the possibility that cannabis may be a primary driver for the remarkable $42 \%$ rise in total pediatric cancer across the USA from 1975 to 2017 [5]. This relates to the general genotoxicity of cannabis and cannabinoids, to the multiplicity of mechanisms by which cannabinoids act genotoxically and / or epigenotoxically and its evident disruption of chromosomal and epigenomic physiology and to the transgenerational transmission of the effects of environmental intoxicants and thereby the multigenerational impacts of widespread and increasing cannabinoid exposure as is implicit in cannabis legalization paradigms.

\section{Cellular and biological mechanisms Genetic and chromosomal pathways}

Significant data indicate that interchromosomal translocations or gene amplifications can upregulate oncogenes or downregulate tumour suppressors. The classically documented action of cannabinoids including tetrahydrocannabinol (THC), cannabidiol and cannabinol to induce end-to-end chromosomal 
Table 5 Mixed effects regression models

\begin{tabular}{|c|c|c|c|c|c|c|}
\hline \multicolumn{3}{|l|}{ Parameter Estimates } & \multicolumn{4}{|c|}{ Model Parameters } \\
\hline Parameter & Estimate (C.I.) & $P$-Value & S.D. & AIC & $\mathrm{BIC}$ & logLik \\
\hline \multicolumn{7}{|l|}{ ADDITIVE MODELS } \\
\hline \multicolumn{7}{|c|}{ Ime (ALL_Rate Cannabis) } \\
\hline Cannabis & $0.33(0.15,0.51)$ & 0.0004 & 0.4689 & 872.1647 & 889.0866 & -432.0824 \\
\hline \multicolumn{7}{|l|}{ Drugs } \\
\hline \multicolumn{7}{|c|}{ Ime (ALL_Rate $\sim$ Cigarettes + Cannabis + AUD + Analgesics + Cocaine $)$} \\
\hline Cannabis & $0.43(0.23,0.62)$ & 2.7E-05 & 0.4668 & 863.5448 & 884.6873 & -426.7724 \\
\hline Cocaine & $10.44(2.01,18.87)$ & 0.0156 & & & & \\
\hline \multicolumn{7}{|l|}{ Drugs, Income \& Ethnicity } \\
\hline \multicolumn{7}{|c|}{ Ime (ALL_Rate $\sim$ Cigarettes + Cannabis + AUD + Analgesics + Cocaine + Income + 5_Races) } \\
\hline Hispanic & $0.45(0.33,0.57)$ & $2.7 \mathrm{E}-12$ & 0.4478 & 813.8363 & 860.2190 & -395.9182 \\
\hline Cigarettes & $5.21(3.52,6.9)$ & 3.0E-09 & & & & \\
\hline Income & $1(0.56,1.44)$ & $1.2 \mathrm{E}-05$ & & & & \\
\hline Cannabis & $0.25(0.06,0.44)$ & 0.0095 & & & & \\
\hline Analgesics & $-4.44(-9.7,0.82)$ & 0.0986 & & & & \\
\hline Asian-American & $-0.14(-0.29,0.02)$ & 0.0833 & & & & \\
\hline AIAN-American & $-4.72(-8.06,-1.39)$ & 0.0057 & & & & \\
\hline African-American & $-0.1(-0.17,-0.03)$ & 0.0056 & & & & \\
\hline \multicolumn{7}{|l|}{ INTERACTIVE MODEL } \\
\hline \multicolumn{7}{|c|}{ Ime (ALL_Rate Cigarettes * Cannabis * AUD + Analgesics + Cocaine + Income + 5_Races) } \\
\hline Hispanic & $0.37(0.28,0.46)$ & 7.0E-15 & 0.4508 & 809.6203 & 851.8063 & -394.8101 \\
\hline Cannabis: AUD & $7.95(4.69,11.22)$ & $2.5 \mathrm{E}-06$ & & & & \\
\hline AUD & $20.43(11.44,29.43)$ & $1.1 \mathrm{E}-05$ & & & & \\
\hline Income & $0.85(0.47,1.23)$ & $1.3 \mathrm{E}-05$ & & & & \\
\hline AIAN-American & $-4.48(-7.56,-1.4)$ & 0.0045 & & & & \\
\hline African-American & $-0.12(-0.19,-0.06)$ & 0.0003 & & & & \\
\hline Cigarettes: Cannabis & $-1.83(-2.52,-1.15)$ & $2.6 \mathrm{E}-07$ & & & & \\
\hline
\end{tabular}

fusions, ring chromosomes and chain chromosomes in sperm [19], and to cause nuclear blebbing and chromosomal bridges between separating nuclei in anaphase and telophase in dividing oocytes and lymphocytes [51-53] constitute in vitro proof of principal that cannabis is at least an indirect chromosomal clastogen as described long ago [19, 54-60]. Genetic lesions underlying ALL have been proposed by several authors [7, 61-64].

The cannabinoids $\Delta 9$-THC, $\Delta 8$-THC, their hydroxymetabolites, cannabinol, cannabidiol, cannabichromene, cannabicyclol and olivetol which shares the C-ring conformation of these cannabinoids were all shown to impair thymidine, uridine and leucine incorporation into lymphocytic DNA, RNA and protein long ago [53]. $\triangle 9$-THC and olivetol were shown to increase lymphocytic chromosomal segregation errors and the number of hypodiploid cells [53].
When normal human lymphocytes from adult volunteers were incubated with micromolar concentrations of $\triangle 9$-THC a significant increase in chromosomal segregation errors was observed [53]. A higher number of chromosomal bridges, anaphase lags, micronuclei, unequal segregations in bipolar divisions and multipolar divisions was noted. The difference in anaphase lags and unequal divisions was significant [53]. The photomicrographs of many chromosomal bridges in telophase nuclei in [53] are very dramatic indeed. Unequal divisions presage the heightened incidence of chromosomal trisomies and monosomies noted epidemiologically in the Introduction. Anaphase lag is a precursor lesion to micronucleus formation which is the primary engine for chromothripsis and chromoanagensis and micronuclei have long been associated with cannabinoid exposure [65]. 
Table 6 Panel regression models

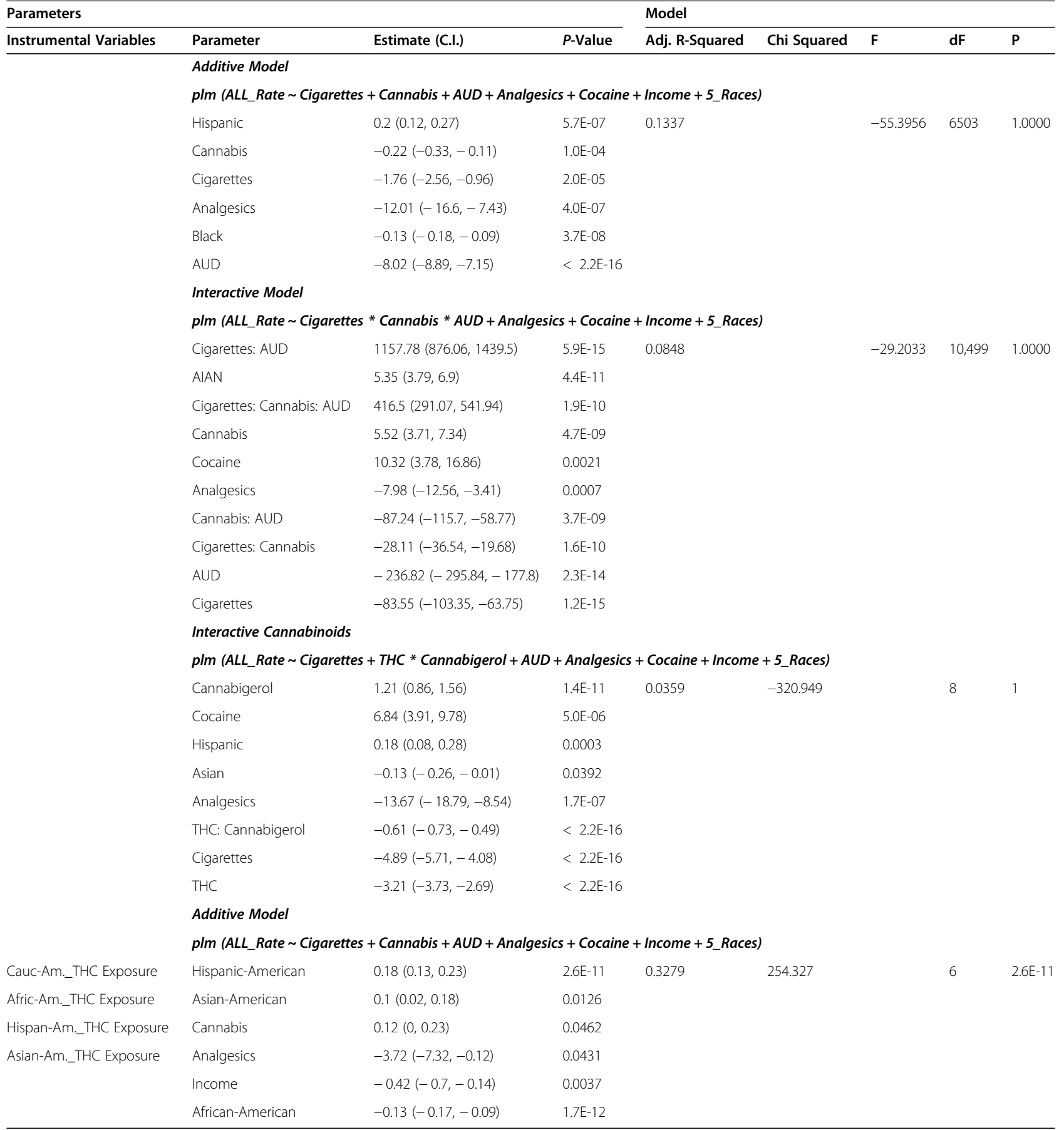

Cannabis has been known to be positive in the micronucleus assay which is one of the primary genotoxicity assays for over fifty years $[65,66]$. Micronuclei have been shown to form when a chromosome becomes derailed and disconnected from the main mitotic spindle during the anaphase separation of the chromatids [67]. This is thought to be due to the impact of cannabis to interfere with the tubulin subunits of the microtubular arms of the mitotic spindle and with the actin subunits of the cellular cytoskeleton [67-69]. Lacking the normal complement of the many enzymes involved in gene maintenance and transcription, the genetic material becomes pulverized and then reannealed in a haphazard manner as a result of the 
normal processes of gene transcription particularly on the lagging strand of DNA. This process thus gives rise to chromothripsis $[67,68]$.

Prenatal cannabis use was linked with Downs syndrome in offspring in an Hawaiian study published in 2007 [70], with Downs syndrome in Colorado, Canada and Australia [71-74] and more recently with Downs syndrome, Trisomies 13 and 18 and the monosomy Turners syndrome in the USA [75]. PCE has also been linked with Deletion $22 \mathrm{q} 11.2$ in the USA in spatiotemporal analyses and in odds ratiobased assessments [75].

Downs syndrome is known to greatly elevate the ALLR from around 3/100,000 to about 5 / 100 [76, 77]. Downs syndrome ALL is a B-Cell ALL RUNX1 positive disorder involving a translocation between chromosomes 12 and 21 [64].

Cannabis use is also linked with chromosome 12 pathophysiology. Testicular cancer invariably involves oncogenic licensing of chromosome 12 usually as an isochromosome $12 \mathrm{p}$ with reduplication of the short arms but alternately intrachromosomal gene amplification has also been described. All four studies examining the link between cannabis use and testicular cancer have been positive [78-81], and three have shown a dose-response relationship [78, 79, 81].

ALL has been described as usually resulting from protooncogene formation and re-arrangements due to translocations between various chromosome combinations including chromosomes 12 and 21 (ETV6-RUNX1), 4 and 11 (MLL-AF4), 1 and 19 (E2A-PBX1), 9 and 22 (BCR-ABL1), trisomy 4 and 10, ETV6-RUNX1-like, DUX4-rearranged, hyperploidy, hypoploidy, and intra-chromosomal rearrangements of chromosome 21 [7]. Interestingly MLL is also known as KMT2a (histone lysine methyltransferase 2a) [64] and both it and RUNX1 have major epigenomic activities.

\section{Epigenomic pathways}

It is established that ALL cells are mostly B-lymphocytes precursors which are arrested in their cellular differentiation and are therefore said to experience a "differentiation block". The epigenetic machinery carried on or near DNA controls the expression of the genes. Hence the epigenetic state controls tissue specificity of cells and their differentiation stage by controlling factors such as DNA methylation, histone methylation and acetylation and post-translational modifications generally, microRNA expression, long non-coding RNA expression, the availability of enhancers to promoters, the activity of non-coding DNA and repeat segments, 3-D position of chromatin within the nucleus, proximity to topologically active domains or transcriptionally active gene "factories" and similar factors [82]. Moreover perturbations of epigenomic control can lead to genetic lesions and reciprocally genetic lesions can induce epigenomic changes [82].

It is important to observe that the genome of embryonic stem cells and precursor cells generally is largely demethylated and more open in its chromosomal conformation making it much more susceptible to genomic and epigenomic insults than the adult genome [83].

In relation to ALL both MLL / KDM2a and RUNX1 (also known as acute myeloid leukaemia protein 1) are key components of the epigenetic machinery. There are 28 million CpG islands in human DNA and their methylation state to a large extent controls the activation of the promoter regions of genes. Methylation of promoter DNA is a key step in leukaemogenesis [83] and several of the leukaemic fusion proteins are epigenomic effectors and change the DNA methylation state globally [63]. RUNX1 directly controls the state of differentiation of haemopoietic precursor cells.

Cannabinoids themselves carry a large epigenomic footprint. THC has been shown to reduce the level of synthesis of nuclear histones, sometimes by half [84, 85]. Marked epigenomically-mediated reduction of brain D2-dopamine receptors has been demonstrated in F1 rodent offspring following PCE [86]. Marked genome wide alteration in nucleus accumbens DNA methylation status has also been shown in another study of rodent F1 offspring after PCE [87-89]. This was replicated recently by a coordinated study of rodent F1 offspring and rat and human sperm [90]. And epigenetically mediated alteration in TH1 and TH2 lymphocyte proliferation in an F1 generation within lymph nodes has also been shown [91].

\section{Metabolism}

Epigenomic modifications of both DNA and histones require small molecules produced from intermediate metabolism such as methyl, acetyl and sumoyl groups. Therefore any process which inhibits cellular metabolism can secondarily perturb the epigenomic state.

Importantly the mitochondria contain $16 \mathrm{~KB}$ of their own DNA which carries the code for some of their proteins. Therefore healthy cellular function requires that the genome of the mitochondria and that of the cell nucleus have coordinated expression of their genomic material. This is known as mitonuclear balance and is mediated both by small molecule metabolites and by malate-aspartate, glycerol-3-phosphate and nicotinamide mononucleotide shuttles and some extra-nuclear sirtuins including sirtuin 2 [92].

In this regard fumarate and succinate are known as oncometabolites and their corresponding disorders, fumarase deficiency and succinate dehydrogenase mutations are known to predispose to malignancy and cause 
Table 7 Lagged panel regression models

\begin{tabular}{|c|c|c|c|c|c|c|c|}
\hline \multicolumn{4}{|l|}{ Parameters } & \multicolumn{4}{|l|}{ Model } \\
\hline Lagged Variables & Parameter & Estimate (C.I.) & $P$-Value & Adj. R-Squared & $\mathbf{F}$ & $\mathrm{dF}$ & $\bar{P}$ \\
\hline & \multicolumn{7}{|l|}{ Interactive Model 2 Lags } \\
\hline & \multicolumn{7}{|c|}{ plm (ALL_Rate $\sim$ Cigarettes * Cannabis * AUD + Analgesics + Cocaine + Income + 5_Races) } \\
\hline Cigarettes, 2 & AUD & $252.85(183.13,322.57)$ & 4.94E-12 & 0.1084 & -21.106 & 12,429 & 1 \\
\hline AUD, 2 & Cannabis: AUD & $98.16(65.56,130.76)$ & 7.31E-09 & & & & \\
\hline Cannabis, 2 & Cigarettes & $60.32(36.61,84.04)$ & 9.01E-07 & & & & \\
\hline Analgesics, 2 & Cigarettes: Cannabis & $24.47(14.69,34.25)$ & $1.34 \mathrm{E}-06$ & & & & \\
\hline \multirow[t]{10}{*}{ Cocaine, 2} & Income & $1.01(0.57,1.44)$ & 6.69E-06 & & & & \\
\hline & Analgesics & $10.02(5.38,14.65)$ & 2.81E-05 & & & & \\
\hline & Cigarettes: Cannabis: AUD & $-372.02(-515.25,-228.79)$ & 5.35E-07 & & & & \\
\hline & African-American & $-0.17(-0.24,-0.11)$ & $1.62 \mathrm{E}-07$ & & & & \\
\hline & Cigarettes: AUD & $-933.3(-1263.65,-602.95)$ & 5.36E-08 & & & & \\
\hline & Cocaine & $-18.93(-25.45,-12.41)$ & 2.39E-08 & & & & \\
\hline & Cannabis & $-6.95(-9.04,-4.86)$ & 2.07E-10 & & & & \\
\hline & White & $-1.7(-2.15,-1.24)$ & 9.93E-13 & & & & \\
\hline & \multicolumn{7}{|l|}{ Interactive Model 4 Lags } \\
\hline & \multicolumn{7}{|c|}{ plm (ALL_Rate $\sim$ Cigarettes $*$ Cannabis $*$ AUD + Analgesics + Cocaine + Income + 5_Races) } \\
\hline Cigarettes, 4 & Cigarettes: Cannabis: AUD & $1080.24(773.54,1386.94)$ & $2.3 \mathrm{E}-11$ & 0.0348 & -24.7061 & 10,363 & 1 \\
\hline AUD, 4 & Cigarettes: AUD & $2872.8(2029.96,3715.63)$ & 9.0E-11 & & & & \\
\hline Cannabis, 4 & Cannabis & $18.57(12.96,24.18)$ & $2.9 \mathrm{E}-10$ & & & & \\
\hline Analgesics, 4 & Hispanic & $0.27(0.15,0.39)$ & 1.1E-05 & & & & \\
\hline \multirow[t]{8}{*}{ Cocaine, 4} & AlAN-American & $-2.93(-5.5,-0.36)$ & 0.0258 & & & & \\
\hline & African-American & $-0.14(-0.21,-0.07)$ & $5.8 \mathrm{E}-05$ & & & & \\
\hline & Cigarettes & $-168.92(-237.17,-100.67)$ & $1.8 \mathrm{E}-06$ & & & & \\
\hline & Cigarettes: Cannabis & $-65.26(-89.6,-40.91)$ & $2.5 \mathrm{E}-07$ & & & & \\
\hline & AUD & $-786.09(-978.02,-594.16)$ & 1.4E-14 & & & & \\
\hline & Cannabis: AUD & $-291.97(-363.15,-220.8)$ & $1.3 \mathrm{E}-14$ & & & & \\
\hline & \multicolumn{7}{|l|}{ Interactive Model 6 Lags } \\
\hline & \multicolumn{7}{|c|}{ plm (ALL_Rate $\sim$ Cigarettes * Cannabis * AUD + Analgesics + Cocaine + Income + 5_Races) } \\
\hline Cigarettes, 6 & Cannabis: AUD & $334.49(201.76,467.22)$ & $1.3 \mathrm{E}-06$ & 0.0748 & -19.0948 & 12,293 & 1 \\
\hline AUD, 6 & AUD & $854.26(489.45,1219.07)$ & $6.6 \mathrm{E}-06$ & & & & \\
\hline Cannabis, 6 & Asian & $0.33(0.18,0.47)$ & $2.8 \mathrm{E}-05$ & & & & \\
\hline Analgesics, 6 & Cigarettes: Cannabis & $84.43(40.2,128.65)$ & 0.0002 & & & & \\
\hline \multirow[t]{8}{*}{ Cocaine, 6} & Cigarettes & $216.5(90.79,342.21)$ & 0.0008 & & & & \\
\hline & Analgesics & $7.94(1.08,14.8)$ & 0.0241 & & & & \\
\hline & Cigarettes: AUD & $-3188.8(-4708.15,-1669.45)$ & $5.1 \mathrm{E}-05$ & & & & \\
\hline & Cannabis & $-23.42(-34.15,-12.7)$ & $2.5 \mathrm{E}-05$ & & & & \\
\hline & Cigarettes: Cannabis: AUD & $-1262.2(-1805.43,-718.97)$ & 7.7E-06 & & & & \\
\hline & Cocaine & $-22.47(-31.69,-13.25)$ & $2.8 \mathrm{E}-06$ & & & & \\
\hline & African-American & $-0.31(-0.41,-0.2)$ & 5.6E-08 & & & & \\
\hline & White & $-2.14(-2.71,-1.58)$ & $1.1 \mathrm{E}-12$ & & & & \\
\hline
\end{tabular}


Table 7 Lagged panel regression models (Continued)

\begin{tabular}{|c|c|c|c|c|c|c|c|}
\hline \multicolumn{4}{|l|}{ Parameters } & \multicolumn{4}{|l|}{ Model } \\
\hline Lagged Variables & Parameter & Estimate (C.I.) & $P$-Value & Adj. R-Squared & $\mathrm{F}$ & $\mathrm{dF}$ & $\mathbf{P}$ \\
\hline & \multicolumn{7}{|l|}{ Interactive Model 8 Lags } \\
\hline & \multicolumn{7}{|c|}{ plm (ALL_Rate $\sim$ Cigarettes $*$ Cannabis $*$ AUD + Analgesics + Cocaine + Income $+5 \_$Races $)$} \\
\hline Cigarettes, 8 & Cigarettes: Cannabis: AUD & $599.85(483.48,716.22)$ & $<2.2 \mathrm{E}-16$ & -0.0014 & -21.9419 & 92,228 & 1 \\
\hline AUD, 8 & Cigarettes: AUD & $923.42(657.01,1189.82)$ & $9.4 \mathrm{E}-11$ & & & & \\
\hline Cannabis, 8 & Cigarettes & $59.16(38.99,79.32)$ & $2.9 \mathrm{E}-08$ & & & & \\
\hline Analgesics, 8 & AIAN-American & $9.11(5.26,12.95)$ & $5.8 \mathrm{E}-06$ & & & & \\
\hline \multirow[t]{5}{*}{ Cocaine, 8} & Asian & $0.36(0.17,0.54)$ & 0.0002 & & & & \\
\hline & African-American & $-0.21(-0.33,-0.08)$ & 0.0011 & & & & \\
\hline & Analgesics & $-19.12(-27.41,-10.82)$ & $1.0 \mathrm{E}-05$ & & & & \\
\hline & AUD & $-225.61(-289.34,-161.88)$ & $4.1 \mathrm{E}-11$ & & & & \\
\hline & Cannabis: AUD & $-142.95(-170.37,-115.54)$ & $<2.2 \mathrm{E}-16$ & & & & \\
\hline
\end{tabular}

germ line mutations as they slow the tricarboxylic acid cycle and interfere with the supply of metabolic substrates to the epigenetic machinery $[82,93]$.

\section{Cannabinoids and mitochondria}

For these reasons it is highly pertinent that cannabinoids inhibit mitochondrial metabolism by many pathways. It is not widely known that the outer mitochondrial membrane of mitochondria carry all the signalling apparatus of the plasmalemma for the

Table 8 Robust regression models

\begin{tabular}{|c|c|c|}
\hline Parameter & Estimate (C.I.) & $P$-Value \\
\hline \multicolumn{3}{|l|}{ Interactive Model - Drugs } \\
\hline \multicolumn{3}{|c|}{$\begin{array}{l}\text { svyglm (ALL_Rate } \sim \text { Cigarettes * Cannabis * AUD + Analgesics + } \\
\text { Cocaine) }\end{array}$} \\
\hline Cigarettes: AUD & $735.98(212.93,1259.02)$ & 0.0110 \\
\hline Cigarettes: Cannabis: AUD & $275.98(78.23,473.74)$ & 0.0115 \\
\hline Cannabis & $3.42(0.52,6.31)$ & 0.0297 \\
\hline Cannabis: AUD & $-65.86(-107.03,-24.69)$ & 0.0045 \\
\hline AUD & $-168.05(-261.96,-74.14)$ & 0.0018 \\
\hline \multicolumn{3}{|c|}{ Interactive Model - Drugs, Income, Ethnicity } \\
\hline \multicolumn{3}{|c|}{$\begin{array}{l}\text { svyglm (ALL_Rate } \sim \text { Cigarettes } * \text { Cannabis } * \text { AUD + Analgesics + } \\
\text { Cocaine + Income + 5_Races) }\end{array}$} \\
\hline AIAN-American & $5.61(3.91,7.31)$ & $8.8 \mathrm{E}-07$ \\
\hline Cigarettes: AUD & $1076.38(277.07,1875.68)$ & 0.0141 \\
\hline Cigarettes: Cannabis: AUD & $372.8(70.03,675.57)$ & 0.0235 \\
\hline Cannabis & $4.75(0.48,9.02)$ & 0.0389 \\
\hline Cigarettes: Cannabis & $-25.81(-48.88,-2.75)$ & 0.0378 \\
\hline Cannabis: AUD & $-74.01(-133.03,-15)$ & 0.0213 \\
\hline Cigarettes & $-80.66(-143.67,-17.64)$ & 0.0190 \\
\hline AUD & $-207.46(-347.32,-67.6)$ & 0.0075 \\
\hline
\end{tabular}

reception and transduction of cannabinoid signals [94-100]. The mitochondrial outer membrane carries cannabinoid type 1 receptors (CB1R's) [95, 96]. This makes sense as cannabinoids are lipid soluble and are easily able to traverse the plasmalemma.

Cannabinoids directly reduce the synthesis of many of the components of the electron transport chain including the F1 ATPase itself $[69,101]$. Cannabinoids reduce the transmembrane potential and lower the proton gradient in many cell types [94, 97-100, 102]. They directly stimulate uncoupling protein 2 [98]. They slow many of the reactions of the tricarboxylic cycle and pyruvate dehydrogenase.

\section{Other pathways}

Apoptosis is a calcium-dependent feed-forward process whereby release of calcium from endoplasmic reticulum stores precipitates massive dumping of calcium from mitochondrial stores which activates the nuclear caspases and other effectors of catastrophic DNA cleavage and cell death pathways [103, 104]. For this reason processes which interfere with calcium channels and calcium signalling make cells more resistant to apoptosis. Many oncoproteins in the leukaemic disease-cluster act in this manner [103, 104]. The vanilloid calcium channels TRPV4 and TRPV6 are implicated in this way [62]. Cannabinoids are known to act at TRPV1 and other vanilloid channels [105-108].

Ceramide signalling is known to be involved in apoptotic pathways $[62,103]$ and is a known target of cannabinoid signalling $[109,110]$.

Cyclic-AMP and adenyl cyclase are known to be key effectors of leukaemic cell apoptosis [62] and are primary targets of cannabinoid and addictive drug signalling generally [111]. 

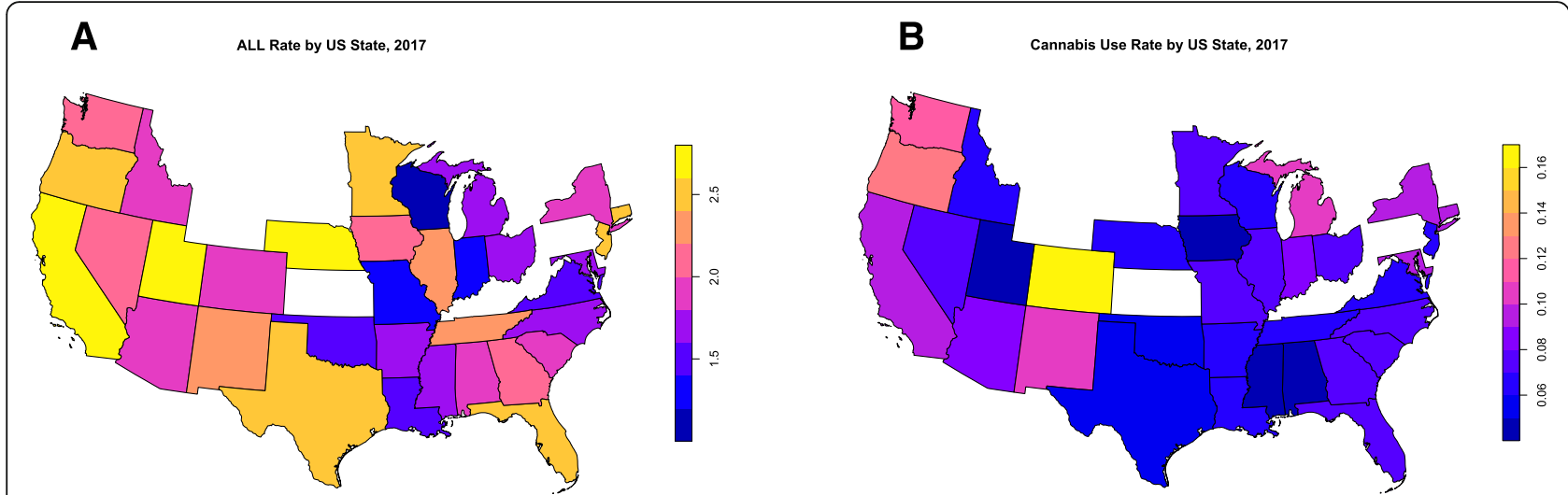

Fig. 9 USA States with data for geospatial analysis (A) as ALL choropleth map for 2017 and (B) Cannabis use choropleth map for 2017

Leukotrienes have been shown to increase oxidative stress and induce DNA damage and be pro-oncogenic [7] and cannabinoid actions via CB1R are well described as often being pro-inflammatory [112-117] including in lymphocytes [118]. This is relevant as heavy cannabis use in young adults is associated in many case reports with aggressive cancers developing at younger age [119-122]. A proinflammatory milieu causes endogenous retrotransposons ("jumping genes") to jump and precipitates genomic instability [123-129]. This process releases repeat sequences of DNA into the cytoplasm where it triggers innate immunity pathways by the cGAS-STING pathway via interferon gamma [123, 127-130]. Once this is stimulated a powerful positive feed-forward loop is established whereby cell-intrinsic inflammation triggers further genomic instability and heightened inflammation. Hence this process has been linked with tumour aggressiveness and metastasis [130].
Indeed it has been suggested that ALL may be a preventable disease based on the association of immune and inflammatory pathways with its pathogenesis [6]. It is interesting to observe that this may in fact be actionable by a bold public health approach to control cannabis for the reasons outlined above.

Reports also exist of cannabinoids being anti-apoptotic by several mechanisms [131-133].

Hence it can be seen that there are many interfaces between cannabinoid, proinflammatory metabolic, mitochondrial and epigenomic pathways which are cancer relevant and make the epidemiologically observed link eminently biologically plausible.

\section{Ethnogenomics}

Many tumours demonstrate significant differential rates by ethnic background. The biological basis of one such interaction was elegantly elucidated by research which traced such differential to a
Additional Links to State Neighbourhood Linkage Network for US Testicular Cancer Network Dataset

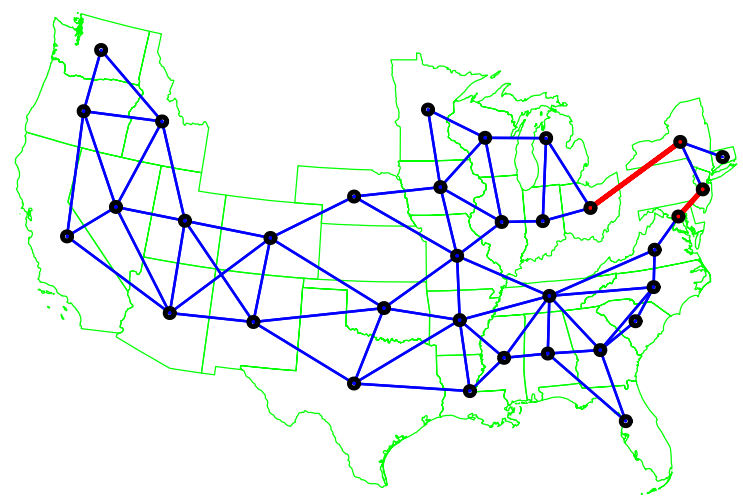

Final Links to State Neighbourhood Linkage Network for US Testicular Cancer Network Dataset

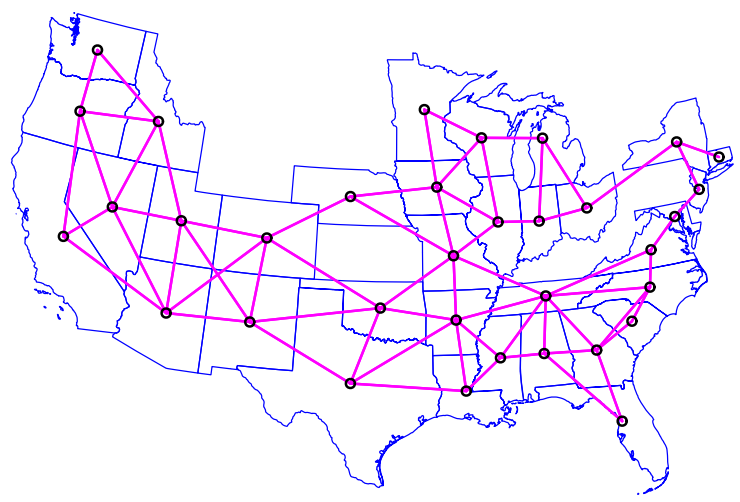

Fig. 10 Choropleth Map of state neighbourhood links (A) edited and (B) final 
Table 9 Geospatiotemporal regression models

\begin{tabular}{|c|c|c|c|c|c|c|c|}
\hline \multicolumn{3}{|l|}{ Parameter } & \multicolumn{5}{|l|}{ Model } \\
\hline Parameter & Estimate (C.I.) & $P$-Value & LogLik & S.D. & Model Parameter & Estimate & $P$-Value \\
\hline \multicolumn{8}{|l|}{ Cannabis Alone } \\
\hline \multicolumn{8}{|l|}{ spreml (ALL_Rate Cannabis) } \\
\hline Cannabis & $0.22(0.09,0.36)$ & 0.0015 & -193.8962 & 0.4040 & phi & 0.5060 & 0.0005 \\
\hline \multicolumn{8}{|l|}{ Additive Model } \\
\hline \multicolumn{8}{|c|}{ spreml (ALL_Rate $\sim$ Cigarettes + Cannabis + AUD + Analgesics + Cocaine $)$} \\
\hline \multirow[t]{2}{*}{ Cannabis } & $0.16(0.06,0.27)$ & 0.0032 & N/A & 0.3869 & phi & 0.4604 & 0.0005 \\
\hline & & & & & rho & -0.3274 & 0.0229 \\
\hline \multicolumn{8}{|l|}{ Interactive Models - Drugs } \\
\hline \multicolumn{8}{|c|}{ spreml (ALL_Rate $\sim$ Cigarettes * Cannabis * AUD + Analgesics + Cocaine) } \\
\hline Cigarettes: Cannabis: AUD & $22.02(10.13,33.91)$ & 0.0003 & -189.4824 & 0.3760 & phi & 0.3669 & 0.0022 \\
\hline Cigarettes: AUD & $45.76(17.83,73.69)$ & 0.0013 & & & rho & -0.3098 & 0.0349 \\
\hline Cannabis: AUD & $-2.39(-4.75,-0.02)$ & 0.0482 & & & lambda & 0.2865 & 0.0162 \\
\hline \multicolumn{8}{|c|}{ Interactive Models - Drugs, Income, Ethnicity } \\
\hline \multicolumn{8}{|c|}{ spreml (ALL_Rate $\sim$ Cigarettes * Cannabis * AUD + Analgesics + Cocaine + Income + 5_Races) } \\
\hline Hispanic & $0.21(0.15,0.26)$ & $8.3 \mathrm{E}-13$ & -170.6536 & N/A & rho & 0.3314 & 0.0007 \\
\hline Asian & $0.12(0.04,0.2)$ & 0.0035 & & & lambda & -0.3523 & 0.0011 \\
\hline Income & $-0.29(-0.57,-0.01)$ & 0.0404 & & & & & \\
\hline African-Am. & $-0.16(-0.21,-0.12)$ & $6.2 \mathrm{E}-14$ & & & & & \\
\hline \multicolumn{8}{|c|}{ Interactive Cannabinoid Models - Drugs, Income, Ethnicity } \\
\hline \multicolumn{8}{|c|}{ spreml (ALL_Rate Cigarettes * THC * CBG + AUD + Analgesics + Cocaine + Income + 5_Races) } \\
\hline Hispanic & $0.23(0.17,0.28)$ & $9.9 \mathrm{E}-15$ & -163.7442 & 0.3325 & phi & 0.0495 & 0.1403 \\
\hline Cannabigerol & $0.26(0.01,0.52)$ & 0.0444 & & & psi & 0.0573 & 0.2640 \\
\hline Cigarettes: THC: Cannabigerol & $-1.18(-1.87,-0.49)$ & 0.0008 & & & rho & 0.1791 & 0.2751 \\
\hline Cigarettes: THC & $-4.96(-7.8,-2.12)$ & 0.0006 & & & lambda & -0.2047 & 0.2159 \\
\hline African-Am. & $-0.13(-0.18,-0.09)$ & $3.4 \mathrm{E}-09$ & & & & & \\
\hline
\end{tabular}

Technical Notes:

phi: - Idiosyncratic component of the spatial error term

psi: - Individual time-invariant component of the spatial error term

rho: - Spatial autoregressive parameter

lambda: - Spatial autocorrelation coefficient

paradoxical activation of a P53 response element at position rs4590952 in the kit P53-RE on chromosome 9 which occurred only in light skinned races [134]. Three loci near this site have previously been identified in prior GWAS's as conferring increased cancer vulnerability [135-137]. P53 is generally known as the guardian of the genome and P53 is widely connected across the genomic and epigenomic machinery of the cell to pause and halt genomic replication in the presence of genotoxic stress. However at this locus genomic stress has the paradoxical effect of inducing activation of genomic replication, apparently to induce the tanning response in the light skinned races and result in melanocyte replication and increased skin protection from ultraviolet light-induced carcinogenesis [134]. Since cannabinoid exposed cells are obviously genotoxically stressed this implies that in fair-skinned races genomic stress can paradoxically stimulate cell replication as implied here.

Other loci have since been described including rs995030 and this is an area of active research enquiry at this time [138].

Since both genetic background and cannabinoid exposure are key factors in determining ALLRs this strongly implies a gene-environment interaction.

\section{Generalizability}

Study results are likely to be generalizable for several reasons. First, we utilize a large database from a populous nation. It would appear that the drug use and cancer incidence data are quite reliable, as are the population-based census data. It is also likely the 
Table 10 Lagged geospatiotemporal regression models

\begin{tabular}{|c|c|c|c|c|c|c|c|c|}
\hline \multirow{4}{*}{$\begin{array}{l}\text { Lagged } \\
\text { Variables }\end{array}$} & \multicolumn{3}{|l|}{ Parameter } & \multicolumn{5}{|l|}{ Model } \\
\hline & Parameter & Estimate (C.I.) & $P$-Value & LogLik & S.D. & Model Parameter & Estimate & $P$-Value \\
\hline & \multicolumn{8}{|l|}{ Spatial Lagging - 1 Spatial Lag } \\
\hline & \multicolumn{8}{|c|}{ spreml (ALL_Rate $\sim$ Cigarettes * THC* Cannabigerol + AUD + Analgesics + Cocaine + Income + 5_Races) } \\
\hline \multirow[t]{9}{*}{$\mathrm{CBG}, 1$} & Hispanic & $0.19(0.14,0.25)$ & $3.8 \mathrm{E}-11$ & -161.6159 & N/A & rho & 0.3329 & 0.0005 \\
\hline & Asian & $0.15(0.07,0.23)$ & 0.0003 & & & lambda & -0.3858 & 0.0002 \\
\hline & THC & $0.47(0.12,0.82)$ & 0.0083 & & & & & \\
\hline & Income & $-0.43(-0.72,-0.13)$ & 0.0045 & & & & & \\
\hline & Cigarettes: THC: Cannabigerol & $-2.67(-3.97,-1.37)$ & $5.9 \mathrm{E}-05$ & & & & & \\
\hline & Cigarettes: THC & $-11.45(-16.99,-5.9)$ & $5.2 \mathrm{E}-05$ & & & & & \\
\hline & African-Am. & $-0.18(-0.22,-0.14)$ & $2.3 \mathrm{E}-16$ & & & & & \\
\hline & \multicolumn{8}{|l|}{ Spatial Lagging - 2 Spatial Lags } \\
\hline & \multicolumn{8}{|c|}{ spreml (ALL_Rate $\sim$ Cigarettes $*$ THC* Cannabigerol + AUD + Analgesics + Cocaine + Income + 5_Races) } \\
\hline \multirow[t]{11}{*}{$\mathrm{CBG}, 2$} & Hispanic & $0.21(0.15,0.27)$ & $3.0 \mathrm{E}-12$ & -162.0804 & N/A & rho & 0.2875 & 0.0065 \\
\hline & Asian & $0.14(0.06,0.22)$ & 0.0006 & & & lambda & -0.3379 & 0.0024 \\
\hline & Cannabigerol & $0.80(0.16,1.43)$ & 0.0140 & & & & & \\
\hline & Cigarettes & $-10.92(-21.53,-0.3)$ & 0.0439 & & & & & \\
\hline & Cigarettes: Cannabigerol & $-3.42(-6.41,-0.42)$ & 0.0253 & & & & & \\
\hline & Income & $-0.37(-0.69,-0.05)$ & 0.0252 & & & & & \\
\hline & Cigarettes: THC & $-8.23(-13.46,-3.01)$ & 0.0020 & & & & & \\
\hline & Cigarettes: THC: Cannabigerol & $-2.35(-3.82,-0.89)$ & 0.0016 & & & & & \\
\hline & African-Am. & $-0.17(-0.21,-0.13)$ & $7.3 \mathrm{E}-15$ & & & & & \\
\hline & \multicolumn{8}{|l|}{ Temporal Lagging - 1 Lag } \\
\hline & \multicolumn{8}{|c|}{ spreml (ALL_Rate $\sim$ Cigarettes * THC* Cannabigerol + AUD + Analgesics + Cocaine + Income + 5_Races) } \\
\hline \multirow[t]{12}{*}{ CBG, 1} & Hispanic & $0.22(0.15,0.29)$ & $1.1 \mathrm{E}-09$ & -139.8349 & N/A & psi & 0.0981 & 0.0430 \\
\hline & Cannabigerol & $0.82(0.25,1.39)$ & 0.0046 & & & rho & 0.1312 & 0.4054 \\
\hline & Asian & $0.12(0.03,0.2)$ & 0.0093 & & & lambda & -0.2103 & 0.1734 \\
\hline & AIAN & $-2.2(-4.08,-0.32)$ & 0.0217 & & & & & \\
\hline & Cigarettes & $-12.59(-22.78,-2.39)$ & 0.0155 & & & & & \\
\hline & Cigarettes: Cannabigerol & $-3.73(-6.58,-0.89)$ & 0.0101 & & & & & \\
\hline & Income & $-0.46(-0.81,-0.11)$ & 0.0099 & & & & & \\
\hline & Cigarettes: THC & $-6.13(-9.34,-2.93)$ & 0.0002 & & & & & \\
\hline & Cigarettes: THC: Cannabigerol & $-1.73(-2.61,-0.86)$ & 9.7E-05 & & & & & \\
\hline & African-Am. & $-0.2(-0.24,-0.15)$ & $<2.2 \mathrm{E}-16$ & & & & & \\
\hline & \multicolumn{8}{|l|}{ Temporal Lagging - 2 Lags } \\
\hline & \multicolumn{8}{|c|}{ spreml (ALL_Rate $\sim$ Cigarettes * THC* Cannabigerol + AUD + Analgesics + Cocaine + Income + 5_Races) } \\
\hline \multirow[t]{6}{*}{$\mathrm{CBG}, 2$} & Hispanic & $0.18(0.12,0.24)$ & 2.0E-09 & -132.1090 & N/A & rho & 0.2545 & 0.0368 \\
\hline & Asian & $0.16(0.07,0.24)$ & 0.0003 & & & lambda & -0.2987 & 0.0169 \\
\hline & Cigarettes: THC & $-3.05(-5.82,-0.28)$ & 0.0308 & & & & & \\
\hline & Cigarettes: THC: Cannabigerol & $-0.86(-1.61,-0.12)$ & 0.0226 & & & & & \\
\hline & Income & $-0.51(-0.81,-0.21)$ & 0.0010 & & & & & \\
\hline & African-Am. & $-0.18(-0.22,-0.14)$ & $6.9 \mathrm{E}-16$ & & & & & \\
\hline
\end{tabular}

Technical Notes:

phi: - Idiosyncratic component of the spatial error term

psi: - Individual time-invariant component of the spatial error term

rho: - Spatial autoregressive parameter

lambda: - Spatial autocorrelation coefficient 
Table 11 Geospatiotemporal ethnic regression models

\begin{tabular}{|c|c|c|c|c|c|c|c|}
\hline \multicolumn{3}{|l|}{ Parameter } & \multicolumn{5}{|l|}{ Model } \\
\hline Parameter & Estimate (C.I.) & $P$-Value & LogLik & S.D. & $\begin{array}{l}\text { Model } \\
\text { Parameter }\end{array}$ & Estimate & $P$-Value \\
\hline \multicolumn{8}{|l|}{ Ethnic THC Exposure - Additive } \\
\hline \multicolumn{8}{|c|}{$\begin{array}{l}\text { spreml (ALL_Rate Caucasian-Am._THC_Exp + African-Am._THC_Exp + Hispanic-Am._THC_Exp +Asian-AM._THC_Exp + AIAN-Am.THC_Exp + } \\
\text { NHPI_THC_Exp) }\end{array}$} \\
\hline HispanicTHC_Expos. & $0.39(0.13,0.65)$ & 0.0038 & -190.5057 & 0.3912 & phi & 0.5148 & 0.0005 \\
\hline NHAfrican-Am.THC_Expos. & $0.34(0.06,0.63)$ & 0.0184 & & & rho & -0.3454 & 0.0099 \\
\hline NHCaucas.-Am.THC_Expos. & $\begin{array}{l}-0.75(-1.25,- \\
0.25)\end{array}$ & 0.0032 & & & lambda & 0.2982 & 0.0063 \\
\hline \multicolumn{8}{|l|}{ Ethnic THC Exposure - Interactive } \\
\hline \multicolumn{8}{|c|}{$\begin{array}{l}\text { spreml (ALL_Rate } \sim \text { Caucasian-Am._THC_Exp } * \text { African-Am._THC_Exp * Hispanic-Am._THC_Exp + Asian-AM._THC_Exp + AIAN-Am.THC_Exp + } \\
\text { NHPI_THC_Exp) }\end{array}$} \\
\hline $\begin{array}{l}\text { NHCaucas._Am.THC_Expos.: NHAfrican-Am.THC_Expos.: } \\
\text { HispanicTHC_Expos. }\end{array}$ & $0.12(0.04,0.2)$ & 0.0031 & -1847.4309 & 0.3817 & phi & 0.5033 & 0.0004 \\
\hline NHCaucas.-Am.THC_Expos. & $-0.06(-0.11,0)$ & 0.0349 & & & rho & -0.4053 & 0.0005 \\
\hline NHCaucas.-Am.THC_Expos:: HispanicTHC_Expos. & $\begin{array}{l}-0.1(-0.16,- \\
0.04)\end{array}$ & 0.0007 & & & lambda & 0.3359 & 0.0003 \\
\hline \multicolumn{8}{|c|}{ Ethnic THC Exposure - Interactive in Substances and in Ethnicity } \\
\hline \multicolumn{8}{|c|}{$\begin{array}{l}\text { spreml (ALL_Rate } \sim \text { Cigarettes } * \text { AUD + Analgesics + Cocaine + Caucasian-Am._THC_Exp }{ }^{*} \text { African-Am._THC_Exp } * \text { Hispanic-Am._THC_Exp }+ \\
\text { Asian-AM._THC_Exp + AIAN-Am.THC_Exp + NHPI_THC_Exp) }\end{array}$} \\
\hline $\begin{array}{l}\text { NHCaucas._Am.THC_Expos.: NHAfrican-Am.THC_Expos.: } \\
\text { HispanicTHC_Expos. }\end{array}$ & $0.12(0.04,0.2)$ & 0.0023 & -180.6319 & 0.3642 & phi & 0.3436 & 0.0021 \\
\hline Cigarettes: AUD & $\begin{array}{l}16.13(3.39, \\
28.87)\end{array}$ & 0.0131 & & & rho & -0.3769 & 0.0016 \\
\hline NHCaucas.-Am.THC_Expos. & $\begin{array}{l}-0.08(-0.16,- \\
0.01)\end{array}$ & 0.0305 & & & lambda & 0.3057 & 0.0014 \\
\hline Cigarettes & $\begin{array}{l}-2.86(-4.67 \\
-1.05)\end{array}$ & 0.0019 & & & & & \\
\hline NHCaucas._Am.THC_Expos.: HispanicTHC_Expos. & $\begin{array}{l}-0.12(-0.18,- \\
0.06)\end{array}$ & 7.5E-05 & & & & & \\
\hline
\end{tabular}

Technical Notes:

phi: - Idiosyncratic component of the spatial error term

psi: - Individual time-invariant component of the spatial error term

rho: - Spatial autoregressive parameter

lambda: - Spatial autocorrelation coefficient

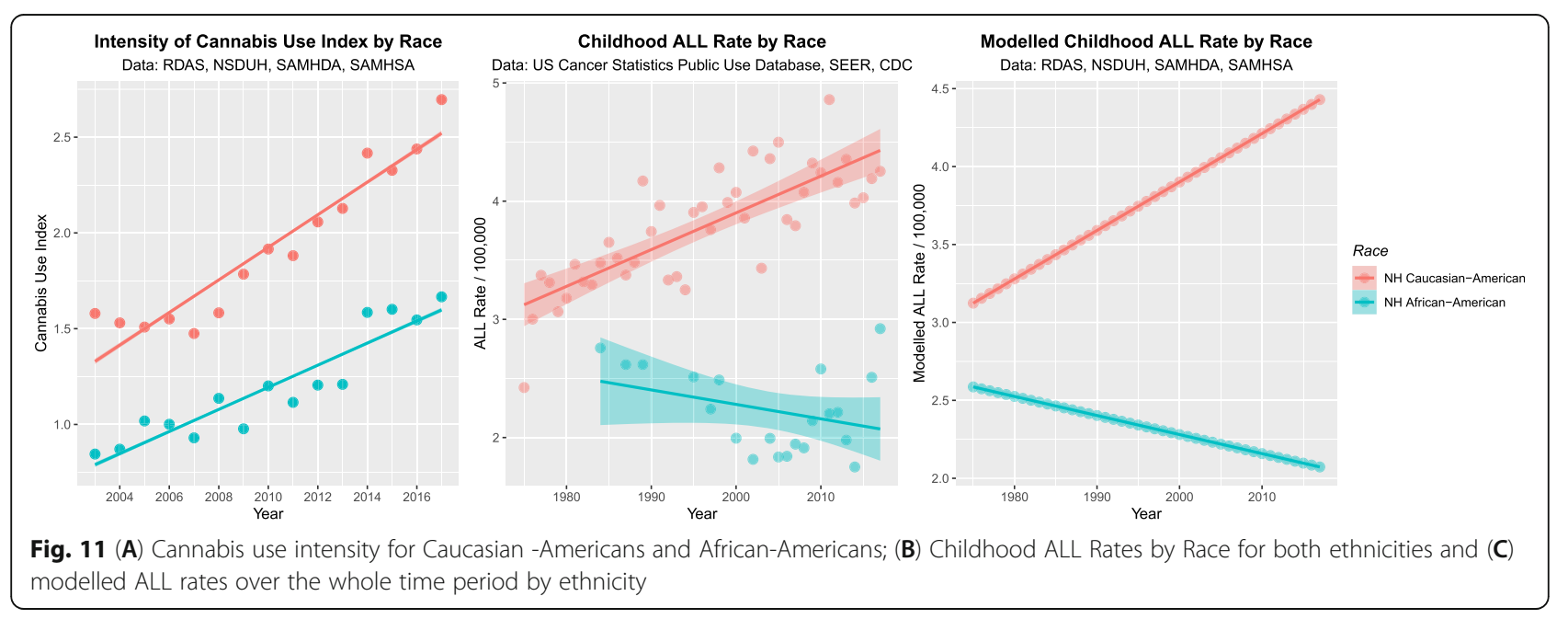




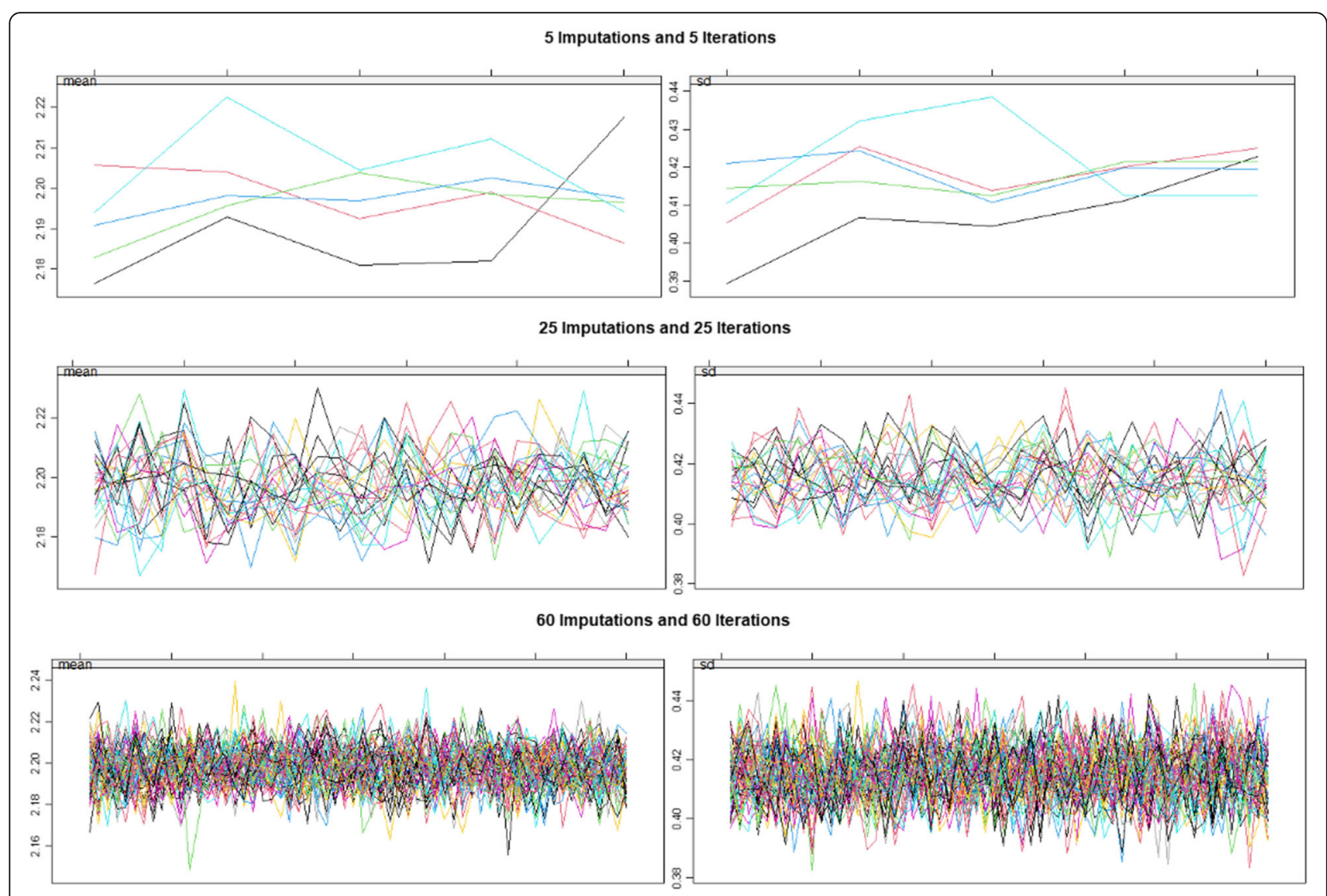

Fig. 12 Stripplots showing convergence of the multiple imputation algorithm with increasing numbers of imputations and iterations to 5 and 5 , 25 and 25 and 60 and 60 respectively

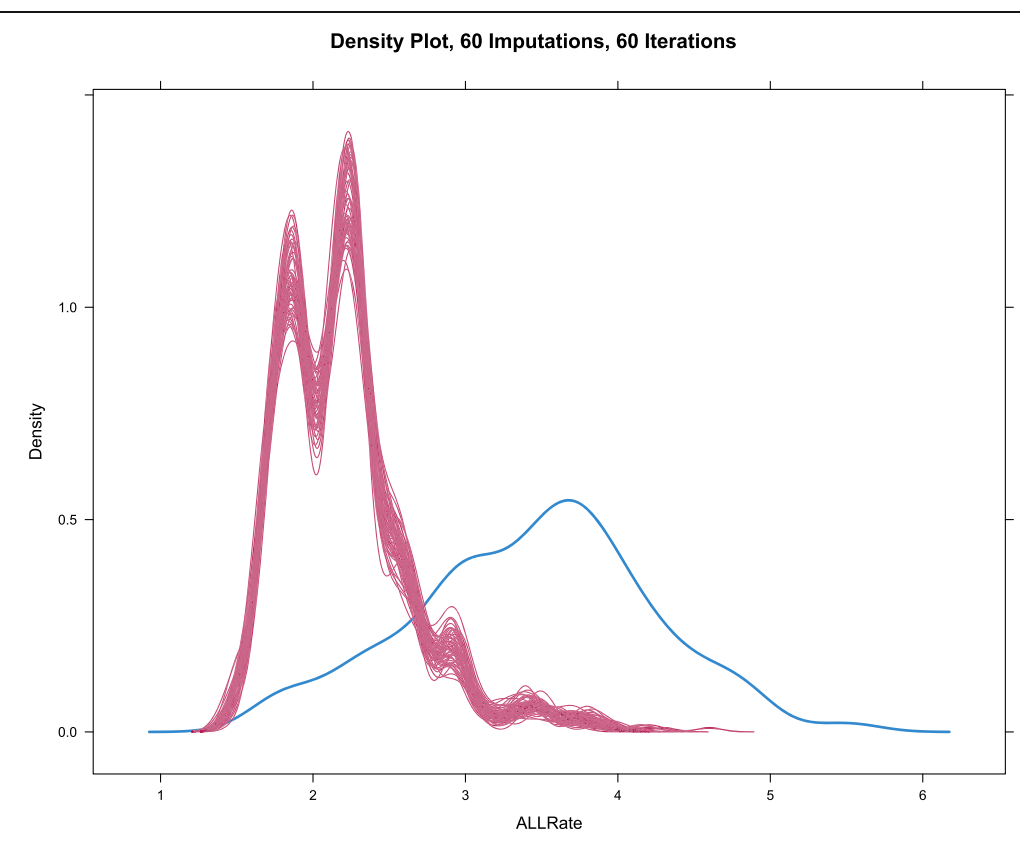

Fig. 13 Density plot of imputed values in the various imputations 
Table 12 Linear models from imputed data

\begin{tabular}{|c|c|c|c|c|c|c|}
\hline \multicolumn{3}{|l|}{ Parameters } & \multicolumn{4}{|l|}{ Model } \\
\hline Parameter & Estimate (C.I.) & $P$-Value & No. Imputa- tions & SD & lambda & FMI \\
\hline \multicolumn{7}{|l|}{ Cannabis Alone } \\
\hline \multicolumn{7}{|c|}{ Im (ALL_Rate Ethnic_THC_Exposure } \\
\hline Ethnic_THC_Exposure & $0.14(0.12,0.17)$ & $3.4 \mathrm{E}-26$ & 60 & 0.2891 & 0.0562 & 0.0583 \\
\hline \multicolumn{7}{|l|}{ Additive Model } \\
\hline \multicolumn{7}{|c|}{ Im (ALLRate $\sim$ Cigarettes + AUD + Ethic_THC_Exposure + Analgesics + Cocaine) } \\
\hline Ethnic_THC_Exposure & $0.53(0.44,0.61)$ & $6.2 \mathrm{E}-31$ & 60 & 0.8246 & 0.0301 & 0.0321 \\
\hline AUD & $9.1(5.3,12.89)$ & $3.1 \mathrm{E}-06$ & & & 0.0301 & 0.0321 \\
\hline Cigarettes & $1.52(0.09,2.95)$ & 0.0371 & & & 0.0294 & 0.0314 \\
\hline
\end{tabular}

Interactive Model

Im (ALLRate Cigarettes + AUD + Ethic_THC_Exposure + Analgesics + Cocaine + Cigarettes: AUD + Cigarettes: Ethnic_Cannabis + AUD: Ethnic_Cannabis)

$\begin{array}{lllll}\text { Ethnic_THC_Exposure } & 0.42(0.35,0.5) & 1.7 \mathrm{E}-27 & 60 & 0.0355 \\ \text { Cocaine } & 10.69(2.47,18.92) & 0.0110 & 0.0335 & 0.0343\end{array}$

Interactive Model with Cannabinoids

Im (ALLRate Cigarettes + AUD + THC + Cannabigerol + Analgesics + Cocaine + Cigarettes: AUD + Cigarettes: Ethnic_Cannabis + AUD: Ethnic_Cannabis)

\begin{tabular}{|c|c|c|c|c|c|c|}
\hline Cigarettes: Ethnic_THC_Exposure & $3.77(3.12,4.42)$ & $5.8 \mathrm{E}-13$ & 60 & 0.6885 & 0.0270 & 0.0290 \\
\hline Cannabigerol & $2.14(1.65,2.63)$ & $2.1 \mathrm{E}-17$ & & & 0.0484 & 0.0505 \\
\hline AUD: Ethnic_THC_Exposure & $6.98(5.08,8.88)$ & $1.2 \mathrm{E}-12$ & & & 0.0251 & 0.0270 \\
\hline Cigarettes & $-5.68(-7.03,-4.33)$ & $4.4 \mathrm{E}-16$ & & & 0.0596 & 0.0617 \\
\hline THC: Cannabigerol & $-19.56(-22.57,-16.55)$ & $1.0 \mathrm{E}-34$ & & & 0.0405 & 0.0425 \\
\hline $\mathrm{THC}$ & $-2.63(-3.03,-2.23)$ & $1.3 \mathrm{E}-35$ & & & 0.0538 & 0.0559 \\
\hline
\end{tabular}

Interactive Model with Ethnicity \& Income

Im (ALLRate Cigarettes + AUD + Ethic_THC_Exposure + Analgesics + Cocaine + Cigarettes: AUD + Cigarettes: Ethnic_Cannabis + AUD: Ethnic_Cannabis + Income + NHWhite + NHAfrican-Am.)

\begin{tabular}{|c|c|c|c|c|c|c|}
\hline Ethnic_THC_Exposure & $0.64(0.55,0.72)$ & $3.1 \mathrm{E}-40$ & 60 & 0.8028 & 0.0352 & 0.0373 \\
\hline Cigarettes: AUD & $27.3(14.38,40.22)$ & 3.7E-05 & & & 0.0328 & 0.0348 \\
\hline Analgesics & $-8.83(-14.57,-3.09)$ & 0.0027 & & & 0.0268 & 0.0288 \\
\hline Income & $-1.73 \mathrm{E}-05(-2.46 \mathrm{E}-05,-1.0 \mathrm{E}-05$ & 3.7E-06 & & & 0.0482 & 0.0502 \\
\hline Black & $-1.56(-2.18,-0.94)$ & $1.1 \mathrm{E}-06$ & & & 0.0371 & 0.0391 \\
\hline White & $-1.28(-1.72,-0.84)$ & 2.6E-08 & & & 0.0313 & 0.0333 \\
\hline \multicolumn{7}{|c|}{ Interactive Model with Intensity Cannabis Use } \\
\hline Cigarettes: Ethnic_THC_Exposure & $2.97(2.61,3.32)$ & $4.80 \mathrm{E}-53$ & 60 & 0.7883 & 0.0206 & 0.0226 \\
\hline Cigarettes: AUD & $-31.33(-44.5,-18.17)$ & $3.53 \mathrm{E}-06$ & & & 0.0434 & 0.0455 \\
\hline NHWhite_Cannabis_Intensity & $-1.32(-1.55,-1.09)$ & $6.34 \mathrm{E}-28$ & & & 0.0420 & 0.0440 \\
\hline
\end{tabular}

Interactive Model with Ethnicity \& Income with Intensity Cannabis Use

\begin{tabular}{|c|c|c|c|c|c|c|}
\hline Cigarettes: Ethnic_THC_Exposure & $4.69(3.77,5.61)$ & $1.0 \mathrm{E}-22$ & 60 & 0.7585 & 0.0231 & 0.0251 \\
\hline Cigarettes: AUD & $150(67.09,232.91)$ & 4.0E-04 & & & 0.0479 & 0.0500 \\
\hline Cocaine & $-11.7(-21.38,-2.02)$ & 0.0181 & & & 0.0447 & 0.0467 \\
\hline Income & $-1.1 \mathrm{E}-05(-2.0 \mathrm{E}-05,-3.0 \mathrm{E}-06)$ & 0.0097 & & & 0.0458 & 0.0478 \\
\hline AUD: Ethnic_THC_Exposure & $-3.51(-6.14,-0.88)$ & 0.0088 & & & 0.0274 & 0.0294 \\
\hline AUD & $-29.6(-49.98,-9.22)$ & 0.0045 & & & 0.0477 & 0.0497 \\
\hline White & $-0.88(-1.34,-0.41)$ & 0.0002 & & & 0.0441 & 0.0462 \\
\hline Analgesics & $-11.6(-17.11,-6.09)$ & $3.8 \mathrm{E}-05$ & & & 0.0316 & 0.0336 \\
\hline Cigarettes & $-17(-22.66,-11.34)$ & 5.1E-09 & & & 0.0394 & 0.0415 \\
\hline NHWhite_Cannabis_Intensity & $-1.58(-1.82,-1.34)$ & $4.2 \mathrm{E}-35$ & & & 0.0472 & 0.0493 \\
\hline
\end{tabular}


Table 13 e-Values

\begin{tabular}{|c|c|c|c|}
\hline Parameter & Estimate (C.I.) & R.R. (C.I.) & E-Values \\
\hline \multicolumn{4}{|l|}{ Linear Models } \\
\hline \multicolumn{4}{|c|}{ Im (ALL_Rate mrjmon) } \\
\hline Cannabis & $0.3(0.18,0.41)$ & $1.94(1.51,2.51)$ & $3.30,2.38$ \\
\hline \multicolumn{4}{|c|}{ Im (ALL_Rate $\sim$ Time ${ }^{*}$ mrjmon) } \\
\hline Cannabis & $\begin{array}{l}30.51(13.22 \\
132.81)\end{array}$ & $\begin{array}{l}2.70 \mathrm{E}+71(1.13 \mathrm{E}+13,6.46 \mathrm{E}+ \\
129)\end{array}$ & $\begin{array}{l}5.40 \mathrm{E}+71,2.25 \mathrm{E}+ \\
13\end{array}$ \\
\hline \multicolumn{4}{|l|}{ Quintiles } \\
\hline \multicolumn{4}{|c|}{ Im (ALL_Rate Quintile) } \\
\hline Quintile 4 & $0.18(0.07,0.29)$ & $1.49(1.15,1.91)$ & $2.34,1.59$ \\
\hline Quintile 5 & $0.19(0.06,0.32)$ & $1.53(1.15,2.04)$ & $2.43,1.57$ \\
\hline \multicolumn{4}{|c|}{ Im (ALL_Rate Year * Quintile) } \\
\hline Quintile 3 & $\begin{array}{l}79.2(26.91 \\
131.49)\end{array}$ & $\begin{array}{l}7.55 \mathrm{E}+76(1.67 \mathrm{E}+26,3.41 \mathrm{E}+ \\
127)\end{array}$ & $\begin{array}{l}1.51 \mathrm{E}+77,3.34 \mathrm{E}+ \\
26\end{array}$ \\
\hline Quintile 4 & $\begin{array}{l}74.23(21.02 \\
127.44)\end{array}$ & $\begin{array}{l}1.13 \mathrm{E}+72(3.23 \mathrm{E}+20,3.96 \mathrm{E}+ \\
123)\end{array}$ & $\begin{array}{l}2.26 \mathrm{E}+72,6.50 \mathrm{E}+ \\
20\end{array}$ \\
\hline Quintile 5 & $61.55(3.2,119.9)$ & $\begin{array}{l}5.54 \mathrm{E}+59(1.65 \mathrm{E}+03,1.85 \mathrm{E}+ \\
116)\end{array}$ & $\begin{array}{l}1.11 \mathrm{E}+60,3.31 \mathrm{E}+ \\
03\end{array}$ \\
\hline \multicolumn{4}{|c|}{ Im (ALL_Rate Year * Dichotomized_Quintiles) } \\
\hline Upper Quintiles & $0.15(0.07,0.22)$ & $\begin{array}{l}1.99 \mathrm{E}+59(1.56 \mathrm{E}+03,2.54 \mathrm{E}+ \\
115)\end{array}$ & $\begin{array}{l}3.99 \mathrm{E}+59,3.13 \mathrm{E}+ \\
03\end{array}$ \\
\hline \multicolumn{4}{|l|}{ Legal Status } \\
\hline \multicolumn{4}{|l|}{ Im (Rate Status) } \\
\hline Legal & $0.3(0.12,0.49)$ & $1.98(1.31,2.98)$ & $3.37,1.95$ \\
\hline Medical & $0.21(0.12,0.31)$ & $1.62(1.30,2.00)$ & $2.62,1.94$ \\
\hline \multicolumn{4}{|c|}{ Im (Rate Year * Status) } \\
\hline Legal & $0.3(0.12,0.49)$ & $1.98(1.31,2.98)$ & $3.37,1.95$ \\
\hline Medical & $0.21(0.12,0.31)$ & $1.62(1.30,2.00)$ & $2.62,1.94$ \\
\hline \multicolumn{4}{|c|}{ Im (Rate $\sim$ Year * Dichotomized Status) } \\
\hline Liberal & $0.11(0.04,0.18)$ & $1.27(1.08,1.49)$ & $1.85,1.38$ \\
\hline \multicolumn{4}{|l|}{ Additive model } \\
\hline \multicolumn{4}{|c|}{ Im (ALL_Rate $\sim$ Cigarettes + AUD + Cannabis + Analgesics + Cocaine) } \\
\hline Cannabis & $0.14(0.03,0.26)$ & $1.40(1.06,1.84)$ & $2.16,1.34$ \\
\hline \multicolumn{4}{|c|}{ MIXED EFFECTS MODELS } \\
\hline \multicolumn{4}{|l|}{ ADDITIVE MODELS } \\
\hline \multicolumn{4}{|c|}{ Ime (ALL_Rate Cannabis) } \\
\hline Cannabis & $0.33(0.15,0.51)$ & $1.30(1.04,2.47)$ & $2.58,1.24$ \\
\hline \multicolumn{4}{|l|}{ Drugs } \\
\hline \multicolumn{4}{|c|}{ Ime (Rate $\sim$ Cigarettes + Cannabis + AUD + Analgesics + Cocaine) } \\
\hline Cannabis & $0.43(0.23,0.62)$ & $2.29(1.56,3.37)$ & $4.02,2.50$ \\
\hline \multicolumn{4}{|c|}{ Drugs, Income \& Ethnicity } \\
\hline \multicolumn{4}{|c|}{ Ime (ALL_Rate $\sim$ Cigarettes + Cannabis + AUD + Analgesics + Cocaine + Income + 5_Races) } \\
\hline Cannabis & $0.25(0.06,0.44)$ & $1.66(1.14,2.44)$ & $2.72,1.53$ \\
\hline \multicolumn{4}{|l|}{ INTERACTIVE MODEL } \\
\hline \multicolumn{4}{|c|}{ Ime (ALL_Rate $\sim$ Cigarettes $*$ Cannabis $*$ AUD + Analgesics + Cocaine + Income + 5_Races) } \\
\hline Cannabis: AUD & $7.95(4.69,11.22)$ & $\begin{array}{l}9.40 E+06(1.29 E+04,6.81 E+ \\
09)\end{array}$ & $\begin{array}{l}1.88 \mathrm{E}+07,2.59 \mathrm{E}+ \\
04\end{array}$ \\
\hline
\end{tabular}


Table 13 e-Values (Continued)

\begin{tabular}{|c|c|c|c|}
\hline Parameter & Estimate (C.I.) & R.R. (C.I.) & E-Values \\
\hline \multicolumn{4}{|l|}{ GEOSPATIAL MODELS } \\
\hline \multicolumn{4}{|l|}{ Cannabis Alone } \\
\hline \multicolumn{4}{|l|}{ spreml (ALL_Rate Cannabis) } \\
\hline Cannabis & $0.22(0.09,0.36)$ & $3.44(1.61,7.36)$ & $6.34,2.60$ \\
\hline \multicolumn{4}{|l|}{ Additive Model } \\
\hline \multicolumn{4}{|c|}{ spreml (ALL_Rate $\sim$ Cigarettes + Cannabis + AUD + Analgesics + Cocaine $)$} \\
\hline Cannabis & $0.16(0.06,0.27)$ & $1.47(1.14,1.90)$ & $2.31,1.54$ \\
\hline \multicolumn{4}{|l|}{ Interactive Models - Drugs } \\
\hline \multicolumn{4}{|c|}{ spreml (ALL_Rate $\sim$ Cigarettes * Cannabis * AUD + Analgesics + Cocaine) } \\
\hline Cigarettes: Cannabis: AUD & $\begin{array}{l}22.02(10.13, \\
33.91)\end{array}$ & $\begin{array}{l}1.38 \mathrm{E}+23(4.65 \mathrm{E}+10,4.11 \mathrm{E}+ \\
35)\end{array}$ & $\begin{array}{l}2.77 \mathrm{E}+23,9.30 \mathrm{E}+ \\
10\end{array}$ \\
\hline \multicolumn{4}{|c|}{ Interactive Cannabinoid Models - Drugs, Income, Ethnicity } \\
\hline \multicolumn{4}{|c|}{ spreml (ALL_Rate Cigarettes * Cannabis * AUD + Analgesics + Cocaine + Income + 5_Races) } \\
\hline Cannabigerol & $0.26(-3.68,4.2)$ & $2.04(1.02,4.11)$ & $3.51,1.16$ \\
\hline \multicolumn{4}{|l|}{ ETHNICITY MODELS } \\
\hline \multicolumn{4}{|l|}{ Ethnic THC Exposure - Additive } \\
\hline \multicolumn{4}{|c|}{$\begin{array}{l}\text { spreml (ALL_Rate } \sim \text { Caucasian-Am._THC_Exp + African-Am._THC_Exp + Hispanic-Am._THC_Exp + Asian-AM._THC_Exp + AIAN-Am.THC_Exp + } \\
\text { NHPI_THC_Exp) }\end{array}$} \\
\hline HispanicTHC_Expos. & $0.39(0.13,0.65)$ & $2.47(1.34,4.54)$ & $4.37,2.01$ \\
\hline NHAfrican-Am.THC_Expos. & $0.34(0.06,0.63)$ & $2.11(1.09,4.07)$ & $3.65,1.43$ \\
\hline
\end{tabular}

Ethnic THC Exposure - Interactive

spreml (ALL_Rate Caucasian-Am._THC_Exp * African-Am._THC_Exp ${ }^{*}$ Hispanic-Am._THC_Exp + Asian-AM._THC_Exp + AIAN-Am.THC_Exp + NHPI_THC_EXP)

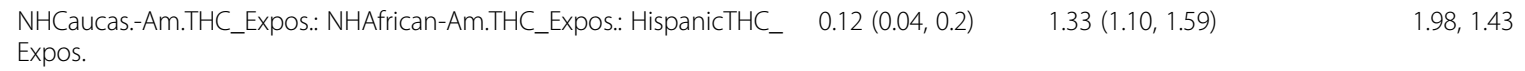

spreml (ALL_Rate $\sim$ Cigarettes ${ }^{*}$ AUD + Analgesics + Cocaine + Caucasian-Am._THC_Exp ${ }^{*}$ African-Am._THC_Exp ${ }^{*}$ Hispanic-Am._THC_Exp + Asian-AM._THC_Exp+AIAN-Am.THC_Exp + NHPI_THC_Exp) NHCaucas.-Am.THC_Expos.: NHAfrican-Am.THC_Expos:: HispanicTHC_ $0.12(0.04,0.2) \quad 1.36(1.12,1.66)$
Expos.

Ethnic Imputed Models

Additive Model

Ethnic_THC_Exposure

$\begin{array}{lll}0.53(0.44,0.61) & 1.78(1.62,1.96) & 2.97,2.64 \\ 0.42(0.35,0.5) & 1.59(1.46,1.72) & 2.55,2.29 \\ & & \\ 2.14(1.65,2.63) & 16.99(8.90,34.42) & 33.47,17.29 \\ 3.77(3.12,4.42) & 146.54(62.25,344.97) & 292.59,124.00 \\ 6.98(5.08,8.88) & 1.01 \mathrm{E}+04(829.80,1.24 \mathrm{E}+05) & \begin{array}{l}2.03 \mathrm{E}+04,1.66 \mathrm{E}+ \\ 03\end{array}\end{array}$

Interactive Model with Race \& Income

Ethic_THC_Exposure

$3.52,3.11$

Interactive Model with Race \& Income \& Cannabis Intensity

Cigarettes: Ethic_THC_Exposure

$4.69(3.77,5.61) \quad 279.13(92.59,841.47) \quad 557.76,184.68$

Cannabis_Use_Intensity

$\mathrm{NH}$ Caucasian-American

$8.93(6.2,11.66) \quad 1.66 \mathrm{E}+52(1.97 \mathrm{E}+36,1.39 \mathrm{E}+$ 
Table 14 List of Minimum e-Values

\begin{tabular}{|c|c|}
\hline No. & Minimum e-Value \\
\hline 1 & $3.94 \mathrm{E}+36$ \\
\hline 2 & $3.34 \mathrm{E}+26$ \\
\hline 3 & $6.50 E+20$ \\
\hline 4 & $2.25 E+13$ \\
\hline 5 & $9.30 E+10$ \\
\hline 6 & $2.54 \mathrm{E}+08$ \\
\hline 7 & $25,900.00$ \\
\hline 8 & 3310.00 \\
\hline 9 & 3130.00 \\
\hline 10 & 1660.00 \\
\hline 11 & 184.68 \\
\hline 12 & 124.00 \\
\hline 13 & 17.29 \\
\hline 14 & 3.11 \\
\hline 15 & 2.64 \\
\hline 16 & 2.6 \\
\hline 17 & 2.5 \\
\hline 18 & 2.38 \\
\hline 19 & 2.29 \\
\hline 20 & 2.01 \\
\hline 21 & 1.95 \\
\hline 22 & 1.95 \\
\hline 23 & 1.94 \\
\hline 24 & 1.94 \\
\hline 25 & 1.59 \\
\hline 26 & 1.57 \\
\hline 27 & 1.54 \\
\hline 28 & 1.53 \\
\hline 29 & 1.48 \\
\hline 30 & 1.43 \\
\hline 31 & 1.43 \\
\hline 32 & 1.38 \\
\hline 33 & 1.34 \\
\hline 34 & 1.24 \\
\hline 35 & 1.16 \\
\hline
\end{tabular}

most accessible dataset in the world relating drug use to ALL incidence. Secondly, we found similar results when data was interrogated by a variety of regression techniques. Thirdly, the results of the causal inference analysis are strongly positive with both inverse probability weighting and e-Value analyses being strongly confirmatory. Finally, findings satisfy eight of nine of Hill's criteria of causality including strength of association, consistency amongst studies, specificity, temporality, coherence with other known data, biological plausibility, dose-response relationships and experimental confirmation [139]. Notwithstanding, as this relationship has not previously been reported elsewhere we feel that further replication in other contexts is important.

It is also noteworthy that study findings apply more broadly across the spectrum of cannabinoids than just implicating THC alone. Regression findings clearly implicated cannabigerol often more powerfully than THC. Positive and significant trends were observed for the bivariate relationship between ALLR and THC, cannabinol, cannabigerol, cannabichromene and cannabidiol. The action of cannabidiol and cannabidivarin to cause double stranded DNA breaks, micronucleus formation and directly oxidize all the bases of DNA, and slow protein DNA and RNA synthesis was noted earlier $[19,54-57,59,60]$.

\section{Strengths and limitations}

This study has a number of strengths and limitations. Its strengths include the use of: a large population dataset and registry controlled data; a variety of advanced statistical methods including space-time regression, instrumental panel regression, and a number of robust and other regression models; spatially and temporally lagged models with robust results throughout; causal inference techniques including inverse probability weighting in multiple models and e-Value calculation; inclusion of a range of relevant potential covariates including other substance exposure, ethnicity, income and the intensity of use of cannabinoids by various ethnicities; and use of well-validated multiple imputation techniques to examine the effects of ethnic differentials in ALLR. The principal limitation of this study relates to the nonavailability of individual patient level substance use data, a limitation which is common to most epidemiological studies of this kind. Indeed because of recall bias, and because individual participants may be confused about whether their pregnancy was cannabinoid affected after cessation of cannabis exposure early in the pregnancy, we advocate the development of a robust biomarker, possibly derived from epigenomic or glycomic analyses as has previously been advanced [140].

\section{Conclusion}

Study data show for the first time that pediatric ALLRs are robustly related to state-level cannabis exposure and to ethnic THC exposure. Prominent dose-response and quintile effects are demonstrated with marked effects of cannabis legalization. Results are confirmed at space-time regression and shown to be causal by techniques of causal inference particularly inverse probability weighting and e-Values, 


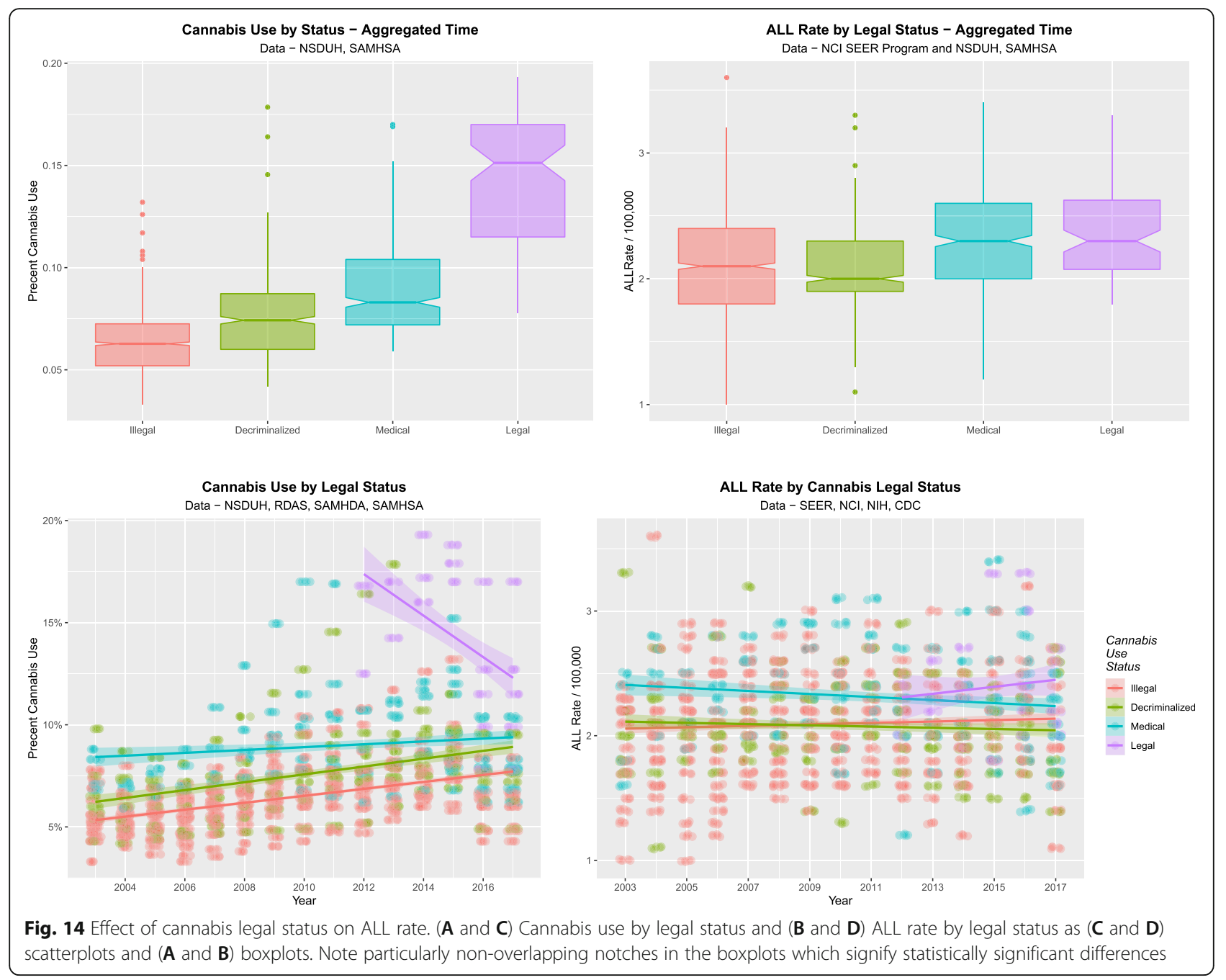

which are all strongly confirmatory. Cannabis legalization was associated with significantly higher ALLRs both when legal status was considered and when dichotomized legal status was reviewed. In so doing we greatly extend prior work, show that the cannabis-ALL link is salient at the population health level, is likely a primary driver of the $93.5 \%$ monotonic rise in ALLRs since 1975, and is a primary contributor to the well described ethnic differentials in ALL incidence, likely related to differential intensity of cannabis exposure and strongly suggesting a gene-environment interaction. Such results are therefore pivotal in re-focussing the pediatric cancer discussion on substance use and cannabinoid exposure in particular. In that ALL is the commonest malignant disorder of the pediatric age group, the present results leave open the possibility that increasing cannabis exposure is a key driver of the marked increases in total pediatric cancers since 1975.
Findings implicate all cannabinoids examined including THC, cannabigerol, cannabichromene, cannabinol and cannabidiol. In that ALL is well described as being due to formation of several protooncogenes and oncoproteins by a series of chromosomal translocations the present clear results add an important mechanistic dimension to the trisomy / monosomy series of defects previously described in association with prenatal cannabis use in addition to anaphase chromosomal mis-segregation [68, 75]. Since pediatric cancer is known to be related to gestational genetic and epigenetic defects these transgenerational impacts add a further major dimension to the cannabis legalization debate which has not been widely considered [141, 142]. Future research directions could include study of this relationship at higher geotemporal resolution and in other contexts and with sensitive objective biomarkers of cannabinoid exposure [140]. 


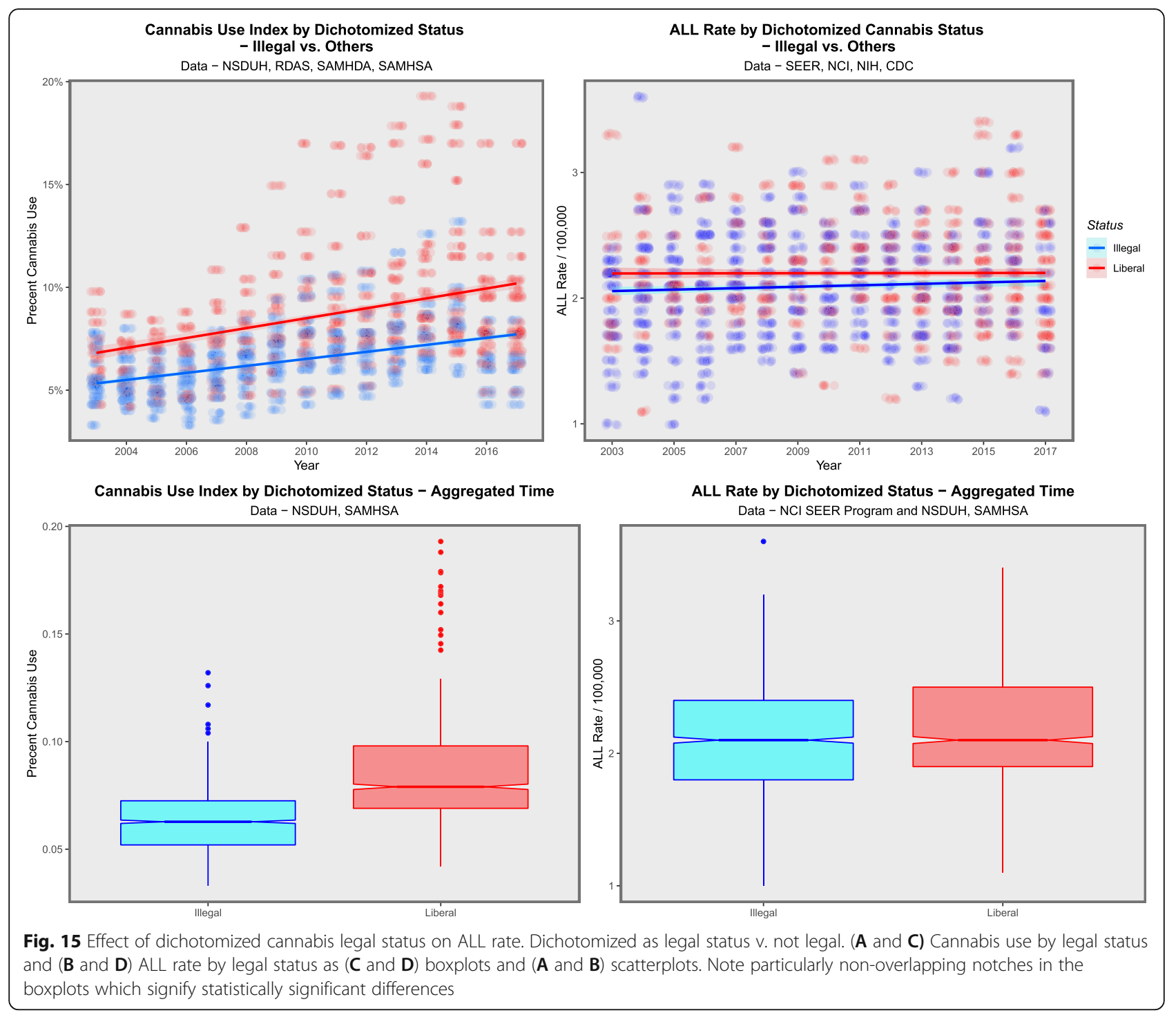

Table 15 Legal Status

\begin{tabular}{|c|c|c|c|c|c|c|c|}
\hline \multirow[t]{2}{*}{ Parameter } & \multicolumn{2}{|l|}{ Parameter } & \multicolumn{5}{|c|}{ Model Parameters } \\
\hline & Estimate (C.I.) & P-Value & SD & R-Squared & $\mathbf{F}$ & $\mathrm{dF}$ & $\mathbf{P}$ \\
\hline \multicolumn{8}{|l|}{ Legal Status } \\
\hline \multicolumn{8}{|l|}{ Im (Rate Status) } \\
\hline Legal & $0.3(0.12,0.49)$ & 0.0013 & 0.4053 & 0.0502 & 9.971 & 3506 & 2.10E-06 \\
\hline Medical & $0.21(0.12,0.31)$ & $1.4 \mathrm{E}-05$ & & & & & \\
\hline \multicolumn{8}{|c|}{ Im (Rate Year * Status) } \\
\hline Legal & $0.3(0.12,0.49)$ & 0.0013 & 0.4053 & 0.0502 & 9.971 & 3506 & 2.10E-06 \\
\hline Medical & $0.21(0.12,0.31)$ & $1.4 \mathrm{E}-05$ & & & & & \\
\hline \multicolumn{8}{|c|}{ Im (Rate Year * Dichotomized Status) } \\
\hline Liberal & $0.11(0.04,0.18)$ & 0.0037 & 0.4128 & 0.0146 & 8.523 & 1508 & 0.0036 \\
\hline \multicolumn{8}{|c|}{ Im (Rate Year * Dichotomized Status) } \\
\hline Legal (v Not Legal) & 1.24E-04 (3.0E-05, 2.2E-04) & 0.0103 & 0.4132 & 0.0127 & 4.288 & 2507 & 0.0142 \\
\hline
\end{tabular}




\section{Abbreviations}

ABL1: Tyrosine protein kinase ABL protooncogene-1; ACOG: American College of Obstetricians and Gynaecologists; AF4: AF4 lymphoid nuclear protein; AIAN: American Indian Alaska Native; ALL: Acute Lymphoid Leukaemia; ALLR: Acute Lymphoid Leukaemia Rate; AUD: Alcohol Use Disorder; BCR: B-Cell Receptor; CAMP: Cyclic Adenosine Monophosphate; CB1R: Cannabinoid Type I Receptor; CD19: B-lymphocyte antigen; CD3: Cluster of differentiation 3; CDC: Centres for Disease Control, Atlanta, Georgia; cGAS: Cytoplasmic Guanosine-Adenosine Synthase;

DNA: Deoxyribonucleic acid; DUX4: Double Homeobox 4; E2A: Basic helixloop-helix binding factors E2A; ETV6: Translocation-Ets-leukaemia virus 6; eValues: Expected values; F1ATPase: F1- ATP synthase (inner mitochondrial membrane); KMT2a: Histone Lysine N-Methyltransferase 2A; lambda: Spatial autocorrelation coefficient; MICE: Multiple Imputation by Chained Equations; MLL: Mixed Lineage Leukaemia; NHPI: Native Hawaiian Pacific Islanders; NSDUH: National Survey of Drug Use and Health; P53: Tumour protein P53; P53-RE: P53-Response Element; PBX1: Pre-B-cell leukaemia transcription factor 1; PCE: Pre-natal cannabis exposure; PCED: PC-esterase domain containing; phi: Idiosyncratic component of the spatial error term; psi: Individual timeinvariant component of the spatial error term; RDAS: Restricted Data Archive System; rho: Spatial autoregressive parameter; RNA: Ribonucleic Acid; RUNX1: Runt-related transcription factor 1; SAMHDA: Substance Abuse Mental Health Data Archive; SAMHSA: Substance Abuse Mental Health Service Administration; SEER: Surveillance Epidemiology and End Results, from CDC; sf: Simple Features; STING: Stimulator of Interferon Genes; THC: $\Delta$ 9-Tetrahydrocannabinol

\section{Supplementary Information}

The online version contains supplementary material available at https://doi. org/10.1186/s12885-021-08598-7.

\section{Additional file 1.}

\section{Acknowledgements}

Not applicable.

\section{Authors' contributions}

ASR assembled the data, designed and conducted the analyses, and wrote the first manuscript draft. GKH provided technical and logistic support, cowrote the paper, assisted with gaining ethical approval, provided advice on manuscript preparation and general guidance to study conduct. All authors have read and approved the manuscript.

\section{Funding}

No funding was provided for this study. No funding organization played any role in the design and conduct of the study; collection, management, analysis, and interpretation of the data; preparation, review, or approval of the manuscript; and decision to submit the manuscript for publication.

\section{Availability of data and materials}

No permissions are required to access the data which was used and collated in this study, e.g. NSDUH study. Data including shapefiles and R programming script is made publicly available on the Mendeley Data Archive at this URL: https://doi.org/10.17632/cf8c43yv62.1 .

\section{Declarations}

\section{Ethics approval and consent to participate}

The Human Research Ethics Committee of the University of Western Australia provided ethical approval for the study to be undertaken 7th June 2019 (No. RA/4/20/4724). Ethics approval was not required to access the data in the first instance. However Ethical approval provided permission to access, analyze and publish all the data obtained.

\section{Consent for publication}

Not applicable.

\section{Competing interests}

The authors declare that they have no competing interests.
Received: 16 November 2020 Accepted: 7 July 2021

Published online: 03 September 2021

\section{References}

1. Institute NC: An Analysis of the National Cancer Institute's Investment in Pediatric Cancer Research. In. Edited by National Cancer Institute of NIH United States Department of Health and Human Services, vol. 1. NIH, USA: $\mathrm{NIH} ; 2013: 20$.

2. Ferlay J, Soerjomataram I, Dikshit R, Eser S, Mathers C, Rebelo M, et al. Cancer incidence and mortality worldwide: sources, methods and major patterns in GLOBOCAN 2012. Int J Cancer. 2015;136(5):E359-86. https://doi. org/10.1002/ijc.29210.

3. Coebergh JW, Reedijk AM, de Vries E, Martos C, Jakab Z, Steliarova-Foucher E, Kamps WA: Leukaemia incidence and survival in children and adolescents in Europe during 1978-1997. Report from the automated childhood Cancer information system project. Eur J Cancer 2006, 42(13):2019-2036.

4. Dockerty JD, Cox B, Cockburn MG. Childhood leukaemias in New Zealand: time trends and ethnic differences. Br J Cancer. 1996;73(9):1141-7. https:// doi.org/10.1038/bjc.1996.219.

5. SEER Explorer [https://seer.cancer.gov/explorer/application.html].

6. Greaves M. A causal mechanism for childhood acute lymphoblastic leukaemia. Nat Rev Cancer. 2018;18(8):471-84. https://doi.org/10.1038/s41 568-018-0015-6.

7. Malouf C, Ottersbach K. Molecular processes involved in B cell acute lymphoblastic leukaemia. Cell Mol Life Sci. 2018;75(3):417-46. https://doi. org/10.1007/s00018-017-2620-z.

8. Robison LL, Buckley JD, Daigle AE, Wells R, Benjamin D, Arthur DC, et al. Maternal drug use and risk of childhood nonlymphoblastic leukemia among offspring. An epidemiologic investigation implicating marijuana (a report from the Childrens Cancer study group). Cancer. 1989;63(10):1904-11. https://doi.org/10.1002/1097-0142(19890515)63:10<1904:.AID-CNCR2820631 006>3.0.CO;2-W

9. Trivers KF, Mertens AC, Ross JA, Steinbuch M, Olshan AF, Robison LL, et al. Parental marijuana use and risk of childhood acute myeloid leukaemia: a report from the Children's Cancer group (United States and Canada). Paediatr Perinat Epidemiol. 2006;20(2):110-8. https://doi.org/10.1111/j.1365-3 016.2006.00700.x

10. Wen WQ, Shu XO, Steinbuch M, Severson RK, Reaman GH, Buckley JD, et al. Paternal military service and risk for childhood leukemia in offspring. Am J Epidemiol. 2000;151(3):231-40. https://doi.org/10.1093/oxfordjournals.aje.a01 0198.

11. McCantz-Katz E. The National Survey of Drug Use and Health: 2019. In. Edited by Substance Abuse and Mental Health Services Administration, US Department of Health and Human Services, vol. 1. Silver Springs, Maryland: SAMHSA, USA Department of Health and Human Services; 2020: 1-63.

12. Dickson B, Mansfield C, Guiahi M, Allshouse AA, Borgelt LM, Sheeder J, et al. Recommendations from Cannabis dispensaries about first-trimester Cannabis use. Obstet Gynecol. 2018;131(6):1031-8. https://doi.org/10.1097/A OG.0000000000002619.

13. Committee on Substance Abuse, Committee on Adolescence; Committee on Substance Abuse Committee on Adolescence. ACOG Committee Opinion: Marijuana Use During Pregnancy and Lactation [ https://www.a cog.org/en/Clinical/Clinical\%20Guidance/Committee\%200pinion/Articles/2 017/10/Marijuana\%20Use\%20During\%20Pregnancy\%20and\%20Lactation ].

14. The impact of marijuana policies on youth: clinical, research, and legal update. Pediatrics 2015, 135(3):584-587.

15. Ammerman $\mathrm{S}$, Ryan $\mathrm{S}$, Adelman WP. The impact of marijuana policies on youth: clinical, research, and legal update. Pediatrics. 2015;135(3):e769-85. https://doi.org/10.1542/peds.2014-4147.

16. Dharmapuri S, Miller K, Klein JD: Marijuana and the Pediatric Population. Pediatrics 2020, 146(2)

17. Wong SS, Wilens TE: Medical Cannabinoids in Children and Adolescents: A Systematic Review. Pediatrics 2017, 140(5).

18. Young-Wolff KC, Tucker $L$, Alexeeff $S$, et al. Trends in self-reported and biochemically tested marijuana use among pregnant females in California from 2009-2016. JAMA. 2017;318(24):2490-1. https://doi.org/10.1001/jama.2 017.17225 .

19. Zimmerman A.M., Zimmerman S., Raj A.Y.: Effects of Cannabinoids on Spermatogensis in Mice. In: Marijuana and Medicine. Volume 1, 1 edn. Edited by Nahas GG, Sutin K.M., Harvey D.J., Agurell S. Totowa, New York: Humana Press; 1999: 347-358. 
20. Russo C, Ferk F, Misik M, Ropek N, Nersesyan A, Mejri D, et al. Low doses of widely consumed cannabinoids (cannabidiol and cannabidivarin) cause DNA damage and chromosomal aberrations in human-derived cells. Arch Toxicol. 2018

21. National Program of Cancer Registries and Surveillance, Epidemiology, and End Results SEER*Stat Database: NPCR and SEER Incidence - U.S. Cancer Statistics Public Use Research Database, 2019 submission (20012017), United States Department of Health and Human Services, Centers for Disease Control and Prevention and National Cancer Institute. Released June 2020. Available at www.cdc.gov/cancer/public-use. [www. cdc.gov/cancer/public-use.]

22. National Survey of Drug Use and Health (NSDUH 2018) [https://www.data files.samhsa.gov/study/national-survey-drug-use-and-health-nsduh-2018-nid1 8757\#].

23. tidycensus: Load US Census Boundary and Attribute Data as 'tidyverse' and 'sf'-Ready Data Frames [https://www.r-pkg.org/pkg/tidycensus ; https://cran.rstudio.com/web/packages/tidycensus/tidycensus.pdf].

24. ElSohly MA, Mehmedic Z, Foster S, Gon C, Chandra S, Church JC. Changes in Cannabis potency over the last 2 decades (1995-2014): analysis of current data in the United States. Biol Psychiatry. 2016;79(7):613-9. https://doi.org/1 0.1016/j.biopsych.2016.01.004.

25. Chandra S, Radwan MM, Majumdar CG, Church JC, Freeman TP, ElSohly MA. New trends in cannabis potency in USA and Europe during the last decade (2008-2017). Eur Arch Psychiatry Clin Neurosci. 2019;269(1):5-15. https://doi. org/10.1007/s00406-019-00983-5.

26. ElSohly MA, Ross SA, Mehmedic Z, Arafat R, Yi B, Banahan BF 3rd. Potency trends of delta9-THC and other cannabinoids in confiscated marijuana from 1980-1997. J Forensic Sci. 2000;45(1):24-30.

27. Legality of cannabis by U.S. jurisdiction [https://en.wikipedia.org/wiki/Lega lity_of_cannabis_by_U.S._jurisdiction].

28. R: A Language and Environment for Statistical Computing [https://www. R-project.org/].

29. Wickham H, Averick M, Bryan J, Chang W, McGowan LD, Francios R, et al. Welcome to the Tidyverse. J Open Source Softw. 2019;4(43):1686-91. https://doi.org/10.21105/joss.01686.

30. Sarkar D.: Lattice: Multivariate Data Visualization with R, vol. 1: Springer; 2008.

31. Pebesma E. Simple features for R: standardized support for spatial vector data. The R Journal. 2018;10(1):439-46. https://doi.org/10.32614/RJ-2018-009.

32. Wickham H. ggplot2: elegant graphics for data analysis, vol. 1. New York: Springer-Verlag; 2016. https://doi.org/10.1007/978-3-319-24277-4.

33. corrgram: Plot a Correlogram [https://CRAN.R-project.org/package=corrgra $\mathrm{m}]$.

34. R package "corrplot": Visualization of a Correlation Matrix [https://github. com/taiyun/corrplot].

35. epiR: Tools for the Analysis of Epidemiological Data. [https://fvas.unimelb. edu.au/research/groups/veterinary-epidemiology-melbourne; https://www.a usvet.com.au/].

36. Lumley T.: Complex Surveys: a guide to analysis using R, vol. 1: Wiley; 2010.

37. Pinheiro J., Bates D., DebRoy S., Sarkar D., Team RC: nlme: Linear and Nonlinear Mixed Effects Models, vol. 1: R: Comprehensive R Archive Network; 2020.

38. Wal W. Geskus R: ipw: an R package for inverse probability weighting. J Stat Softw. 2011;43(13). https://doi.org/10.18637/jss.v043.113.

39. Package 'plm' [https://cran.r-project.org/web/packages/plm/plm.pdf].

40. Package 'EValue' [https://cran.r-project.org/web/packages/EValue/EValue. pdf].

41. Bivand R, Anselin L, Berke O, Bernat A, Carvalho M, Chun Y, et al. The spdep package. In: CRAN. 2007:1-143.

42. Millo G, Piras G. Package 'splm'. In.: CRAN. 2018:1-27.

43. Millo G. Maximum likelihood estimation of spatially and serially correlated panels with random effects. Computational Statistics \& Data Analysis. 2014; 71:914-33. https://doi.org/10.1016/j.csda.2013.07.024.

44. Kapoor M, Kelejian HH, Prucha IR. Panel data models with spatially correlated error components. J Econ. 2007;140(1):97-130. https://doi.org/1 0.1016/j.jeconom.2006.09.004

45. Croissant Y, Millo G. Panel data econometrics with R, vol. 1. Oxford, United Kingdom: John Wiley and Sons; 2019.

46. Van Buuren S, Groothuis-Oudshoorn K. Mice: multivariate imputation by chained equations. J Stat Softw. 2011:45(3):1-67.
47. van Buuren S. Flexible imputation of missing data, vol. 1. Boca Raton, Florida, USA: CRC Press; 2018. https://doi.org/10.1201/9780429492259.

48. National Survey of Drug Use and Health 2018, NSDUH [https://www.samhsa. gov/data/all-reports].

49. VanderWeele TJ, Ding P, Mathur M. Technical considerations in the use of the E-value. Journal of Causal Inference. 2019;7(2):1-11.

50. Hasin DS, Sarvet AL, Cerda M, Keyes KM, Stohl M, Galea S, et al. US adult illicit Cannabis use, Cannabis use disorder, and medical marijuana Laws: 1991-1992 to 2012-2013. JAMA Psychiatry. 2017;74(6):579-88. https://doi. org/10.1001/jamapsychiatry.2017.0724.

51. Morishima A. Effects of cannabis and natural cannabinoids on chromosomes and ova. NIDA Res Monogr. 1984;44:25-45.

52. Morishima A, Henrich RT, Jayaraman J, Nahas GG. Hypoploid metaphases in cultured lymphocytes of marihuana smokers. Adv Biosci. 1978;22-23:371-6. https://doi.org/10.1016/b978-0-08-023759-6.50032-9.

53. Henrich RT, Nogawa T, Morishima A. In vitro induction of segregational errors of chromosomes by natural cannabinoids in normal human lymphocytes. Environ Mutagen. 1980;2(2):139-47. https://doi.org/10.1002/ em.2860020206.

54. McClean DK, Zimmerman AM. Action of delta 9-tetrahydrocannabinol on cell division and macromolecular synthesis in division-synchronized protozoa. Pharmacology. 1976;14(4):307-21. https://doi.org/10.1159/00013 6610.

55. Thomas J, Tilak S, Zimmerman S, Zimmerman AM. Action of delta 9tetrahydrocannabinol on the pool of acid soluble nucleotides. Cytobios. 1984;40(158):71-85.

56. Tahir SK, Trogadis JE, Stevens JK, Zimmerman AM. Cytoskeletal organization following cannabinoid treatment in undifferentiated and differentiated PC12 cells. Biochem Cell Biol. 1992;70(10-11):1159-73. https://doi.org/10.113 9/092-162.

57. Parker S.J., Zuckerman B.S., Zimmermann A.M.: The Effects of Maternal Marijuana Use During Pregnancy on Fetal Growth. In: Marijuana in Medicine. Volume 1, edn. Edited by Nahas GG, Sutin K.M., Harvey D.J., Agurell S. Totowa, New York: Humana Press; 1999: 461-468.

58. Zimmerman S, Zimmerman AM. Genetic effects of marijuana. The International journal of the addictions. 1990;25(1A):19-33. https://doi.org/1 0.3109/10826089009067003.

59. Zimmerman AM, Raj AY. Influence of cannabinoids on somatic cells in vivo. Pharmacology. 1980;21(4):277-87. https://doi.org/10.1159/000137442.

60. Tahir SK, Zimmerman AM. Influence of marihuana on cellular structures and biochemical activities. Pharmacol Biochem Behav. 1991;40(3):617-23. https:// doi.org/10.1016/0091-3057(91)90372-9.

61. Terwilliger T, Abdul-Hay M. Acute lymphoblastic leukemia: a comprehensive review and 2017 update. Blood Cancer J. 2017;7(6):e577. https://doi.org/10.1 038/bcj.2017.53.

62. Chatterton Z, Morenos L, Mechinaud F, Ashley DM, Craig JM, Sexton-Oates A, et al. Epigenetic deregulation in pediatric acute lymphoblastic leukemia. Epigenetics. 2014;9(3):459-67. https://doi.org/10.4161/epi.27585.

63. Nordlund J, Bäcklin CL, Zachariadis V, Cavelier L, Dahlberg J, Öfverholm I, et al. DNA methylation-based subtype prediction for pediatric acute lymphoblastic leukemia. Clin Epigenetics. 2015;7(1):11. https://doi.org/10.11 86/s13148-014-0039-z.

64. Tasian SK, Hunger SP. Genomic characterization of paediatric acute lymphoblastic leukaemia: an opportunity for precision medicine therapeutics. Br J Haematol. 2017;176(6):867-82. https://doi.org/10.1111/ bjh.14474.

65. Hall W, Degenhardt L. Adverse health effects of non-medical cannabis use. Lancet. 2009;374(9698):1383-91. https://doi.org/10.1016/S0140-6736(09)6103 7-0.

66. Hall W. The adverse health effects of cannabis use: what are they, and what are their implications for policy? Int J Drug Policy. 2009;20(6):458-66. https:// doi.org/10.1016/j.drugpo.2009.02.013.

67. Zhang CZ, Spektor A, Cornils H, Francis JM, Jackson EK, Liu S, et al. Chromothripsis from DNA damage in micronuclei. Nature. 2015;522(7555): 179-84. https://doi.org/10.1038/nature14493.

68. Reece AS, Hulse GK. Chromothripsis and epigenomics complete causality criteria for cannabis- and addiction-connected carcinogenicity, congenital toxicity and heritable genotoxicity. Mutat Res. 2016;789:15-25. https://doi. org/10.1016/j.mrfmmm.2016.05.002.

69. Wang J, Yuan W, Li MD. Genes and pathways co-associated with the exposure to multiple drugs of abuse, including alcohol, amphetamine/ 
methamphetamine, cocaine, marijuana, morphine, and/or nicotine: a review of proteomics analyses. Mol Neurobiol. 2011;44(3):269-86. https://doi.org/1 0.1007/s12035-011-8202-4.

70. Forrester MB, Merz RD. Risk of selected birth defects with prenatal illicit drug use, Hawaii, 1986-2002. J Toxicol Environ Health. 2007;70(1):7-18. https://doi.org/10.1080/15287390600748799.

71. Reece AS, Hulse GK. Cannabis teratology explains current patterns of Coloradan congenital defects: the contribution of increased cannabinoid exposure to rising Teratological trends. Clin Pediatr (Phila). 2019;58(10): 1085-123. https://doi.org/10.1177/0009922819861281.

72. Reece AS, Hulse GK. Broad Spectrum Epidemiological Contribution of Cannabis and Other Substances to the Teratological Profile of Northern New South Wales: Geospatial and Causal Inference Analysis. 2020;21(1):75103.

73. Reece AS, Hulse GK. Canadian Cannabis Consumption and Patterns of Congenital Anomalies: An Ecological Geospatial Analysis. J Add Med. 2020; 14(5):e195-210.

74. Reece AS, Hulse GK. Cannabis teratology explains current patterns of Coloradan congenital defects: the contribution of increased cannabinoid exposure to rising Teratological trends. Clin Pediatr. 2019;58(10):1085-123. https://doi.org/10.1177/0009922819861281.

75. Reece AS, Hulse GK. Cannabis in pregnancy - rejoinder. Psychiatric Times: Exposition and Cautionary Tales; 2020. In Press

76. Birger $Y$, Shiloh R, Izraeli S. Mechanisms of leukemia evolution: lessons from a congenital syndrome. Cancer Cell. 2019;36(2):115-7. https://doi.org/10.101 6/j.ccell.2019.07.004.

77. Labuhn M, Perkins K, Matzk S, Varghese L, Garnett C, Papaemmanuil E, et al. Mechanisms of progression of myeloid Preleukemia to transformed myeloid leukemia in children with Down syndrome. Cancer Cell. 2019;36(2):123-38 e110. https://doi.org/10.1016/j.ccell.2019.06.007.

78. Callaghan RC, Allebeck P, Akre O, McGlynn KA, Sidorchuk A. Cannabis use and incidence of testicular Cancer: a 42-year follow-up of Swedish men between 1970 and 2011. Cancer Epidemiol Biomark Prev. 2017;26(11):164452. https://doi.org/10.1158/1055-9965.EPI-17-0428.

79. Daling JR, Doody DR, Sun X, Trabert BL, Weiss NS, Chen C, et al. Association of marijuana use and the incidence of testicular germ cell tumors. Cancer. 2009;115(6):1215-23. https://doi.org/10.1002/cncr.24159.

80. Lacson JC, Carroll JD, Tuazon E, Castelao EJ, Bernstein L, Cortessis VK Population-based case-control study of recreational drug use and testis cancer risk confirms an association between marijuana use and nonseminoma risk. Cancer. 2012;118(21):5374-83. https:/doi.org/10.1002/cncr.27554.

81. Trabert B, Sigurdson AJ, Sweeney AM, Strom SS, McGlynn KA. Marijuana use and testicular germ cell tumors. Cancer. 2011;117(4):848-53. https://doi. org/10.1002/cncr.25499.

82. Bates SE. Epigenetic therapies for Cancer. N Engl J Med. 2020;383(7):650-63. https://doi.org/10.1056/NEJMra1805035.

83. Bröske AM, Vockentanz L, Kharazi S, Huska MR, Mancini E, Scheller M, et al. DNA methylation protects hematopoietic stem cell multipotency from myeloerythroid restriction. Nat Genet. 2009;41(11):1207-15. https://doi.org/1 0.1038/ng.463

84. Mon MJ, Haas AE, Stein JL, Stein GS. Influence of psychoactive and nonpsychoactive cannabinoids on cell proliferation and macromolecular biosynthesis in human cells. Biochem Pharmacol. 1981;30(1):31-43. https:// doi.org/10.1016/0006-2952(81)90281-1.

85. Mon MJ, Haas AE, Stein JL, Stein GS. Influence of psychoactive and nonpsychoactive cannabinoids on chromatin structure and function in human cells. Biochem Pharmacol. 1981;30(1):45-58. https://doi.org/10.1016/ 0006-2952(81)90282-3.

86. DiNieri JA, Wang $X$, Szutorisz H, Spano SM, Kaur J, Casaccia P, et al. Maternal cannabis use alters ventral striatal dopamine D2 gene regulation in the offspring. Biol Psychiatry. 2011;70(8):763-9. https://doi.org/10.1016/j. biopsych.2011.06.027.

87. Szutorisz H, Hurd YL. Epigenetic effects of Cannabis exposure. Biol Psychiatry. 2016;79(7):586-94. https://doi.org/10.1016/j.biopsych.2015.09.014.

88. Watson CT, Szutorisz H, Garg P, Martin Q, Landry JA, Sharp AJ, Hurd YL. Genome-Wide DNA Methylation Profiling Reveals Epigenetic Changes in the Rat Nucleus Accumbens Associated With Cross-Generational Effects of Adolescent THC Exposure. Neuropsychopharmacology. 2015;40(13):29933005.

89. Szutorisz H, DiNieri JA, Sweet E, Egervari G, Michaelides M, Carter JM, et al. Parental THC exposure leads to compulsive heroin-seeking and altered striatal synaptic plasticity in the subsequent generation. Neuropsychopharmacology. 2014;39(6):1315-23. https://doi.org/10.1038/ npp.2013.352.

90. Murphy SK, Itchon-Ramos N, Visco Z, Huang Z, Grenier C, Schrott R, et al. Cannabinoid exposure and altered DNA methylation in rat and human sperm. Epigenetics. 2018;13(12):1208-21. https://doi.org/10.1080/15592294.2 018.1554521.

91. Yang X, Hegde VL, Rao R, Zhang J, Nagarkatti PS, Nagarkatti M. Histone modifications are associated with Delta9-tetrahydrocannabinol-mediated alterations in antigen-specific T cell responses. J Biol Chem. 2014;289(27): 18707-18. https://doi.org/10.1074/jbc.M113.545210.

92. Canto C, Menzies KJ, Auwerx J. NAD(+) metabolism and the control of energy homeostasis: a balancing act between mitochondria and the nucleus. Cell Metab. 2015;22(1):31-53. https://doi.org/10.1016/j.cmet.2015.05.023.

93. Lorenzato A, Olivero M, Perro M, Brière JJ, Rustin P, Di Renzo MF. A cancerpredisposing "hot spot" mutation of the fumarase gene creates a dominant negative protein. Int J Cancer. 2008;122(4):947-51. https://doi.org/10.1002/ ijc.23209.

94. Benard G, Massa F, Puente N, Lourenco J, Bellocchio L, Soria-Gomez E, et al. Mitochondrial $\mathrm{CB}(1)$ receptors regulate neuronal energy metabolism. Nat Neurosci. 2012;15(4):558-64. https://doi.org/10.1038/nn.3053.

95. Hebert-Chatelain E, Desprez T, Serrat R, Bellocchio L, Soria-Gomez E, Busquets-Garcia A, et al. A cannabinoid link between mitochondria and memory. Nature. 2016;539(7630):555-9. https://doi.org/10.1038/nature20127.

96. Hebert-Chatelain E, Reguero L, Puente N, Lutz B, Chaouloff F, Rossignol R, et al. Cannabinoid control of brain bioenergetics: exploring the subcellular localization of the CB1 receptor. Mol Metab. 2014;3(4):495-504. https://doi. org/10.1016/j.molmet.2014.03.007.

97. Jimenez-Blasco D, Busquets-Garcia A, Hebert-Chatelain E, Serrat R, VicenteGutierrez C, loannidou C, et al. Glucose metabolism links astroglial mitochondria to cannabinoid effects. Nature. 2020;583(7817):603-8. https:// doi.org/10.1038/s41586-020-2470-y.

98. Koch M, Varela L, Kim JG, Kim JD, Hernandez-Nuno F, Simonds SE, et al. Hypothalamic POMC neurons promote cannabinoid-induced feeding. Nature. 2015;519(7541):45-50. https://doi.org/10.1038/nature14260.

99. Mahoney JM, Harris RA. Effect of 9 -tetrahydrocannabinol on mitochondrial processes. Biochem Pharmacol. 1972;21(9):1217-26. https://doi.org/10.1016/ 0006-2952(72)90283-3.

100. Wolff V, Schlagowski Al, Rouyer $O$, Charles AL, Singh F, Auger C, et al. Tetrahydrocannabinol induces brain mitochondrial respiratory chain dysfunction and increases oxidative stress: a potential mechanism involved in cannabis-related stroke. Biomed Res Int. 2015;2015:323706.

101. Rubino T, Realini N, Braida D, Alberio T, Capurro V, Vigano D, et al. The depressive phenotype induced in adult female rats by adolescent exposure to THC is associated with cognitive impairment and altered neuroplasticity in the prefrontal cortex. Neurotox Res. 2009;15(4):291-302. https://doi.org/1 0.1007/s12640-009-9031-3.

102. Bartova A, Birmingham MK. Effect of delta9-tetrahydrocannabinol on mitochondrial NADH-oxidase activity. J Biol Chem. 1976;251(16):5002-6. https://doi.org/10.1016/S0021-9258(17)33213-1.

103. Mattson MP, Chan SL. Calcium orchestrates apoptosis. Nat Cell Biol. 2003; 5(12):1041-3. https://doi.org/10.1038/ncb1203-1041.

104. Pedersen SF, Stock C. Ion channels and transporters in cancer: pathophysiology, regulation, and clinical potential. Cancer Res. 2013;73(6): 1658-61. https://doi.org/10.1158/0008-5472.CAN-12-4188.

105. Medeiros P, Oliveira-Silva M, Negrini-Ferrari SE, Medeiros AC, Elias-Filho DH, Coimbra NC, et al. CB(1)-cannabinoid-, TRPV(1)-vanilloid- and NMDAglutamatergic-receptor-signalling systems interact in the prelimbic cerebral cortex to control neuropathic pain symptoms. Brain Res Bull. 2020;165:11828. https://doi.org/10.1016/j.brainresbull.2020.09.013.

106. Muller C, Lynch DL, Hurst DP, Reggio PH. A closer look at anandamide interaction with TRPV1. Front Mol Biosci. 2020;7:144. https://doi.org/10.3389/ fmolb.2020.00144.

107. Quiñonez-Bastidas GN, Palomino-Hernández O, López-Ortíz M, RochaGonzález HI, González-Anduaga GM, Regla I, et al. Antiallodynic effect of PhAR-DBH-me involves cannabinoid and TRPV1 receptors. Pharmacol Res Perspect. 2020;8(5):e00663. https://doi.org/10.1002/prp2.663.

108. Wi R, Chung YC, Jin BK. Functional crosstalk between CB and TRPV1 receptors protects nigrostriatal dopaminergic neurons in the MPTP model of Parkinson's disease. J Immunol Res. 2020;2020:5093493. 
109. Di Scala C, Fantini J, Yahi N, Barrantes FJ, Chahinian H. Anandamide Revisited: How Cholesterol and Ceramides Control Receptor-Dependent and Receptor-Independent Signal Transmission Pathways of a Lipid Neurotransmitter. Biomolecules. 2018;8(2):31-52.

110. Yang J, Tian Y, Zheng R, Li L, Qiu F. Endocannabinoid system and the expression of endogenous ceramides in human hepatocellular carcinoma. Oncol Lett. 2019;18(2):1530-8. https://doi.org/10.3892/ol.2019.10399.

111. Volkow ND, Baler RD, Compton WM, Weiss SR. Adverse health effects of marijuana use. N Engl J Med. 2014;370(23):2219-27. https://doi.org/10.1056/ NEJMra1402309.

112. Benamar K, Yondorf M, Geller EB, Eisenstein TK, Adler MW. Physiological evidence for interaction between the HIV-1 co-receptor CXCR4 and the cannabinoid system in the brain. Br J Pharmacol. 2009;157(7):1225-31. https://doi.org/10.1111/j.1476-5381.2009.00285.x.

113. Chandra LC, Kumar V, Torben W, Vande Stouwe C, Winsauer P, Amedee A, et al. Chronic administration of Delta9-tetrahydrocannabinol induces intestinal anti-inflammatory microRNA expression during acute simian immunodeficiency virus infection of rhesus macaques. J Virol. 2015;89(2): 1168-81. https://doi.org/10.1128/JVI.01754-14.

114. Chiurchiu V. Endocannabinoids and immunity. Cannabis Cannabinoid Res. 2016:1(1):59-66. https://doi.org/10.1089/can.2016.0002.

115. Eisenstein TK, Meissler JJ. Effects of cannabinoids on T-cell function and resistance to infection. J Neurolmmune Pharmacol. 2015;10(2):204-16. https://doi.org/10.1007/s11481-015-9603-3.

116. Greineisen WE, Turner $\mathrm{H}$. Immunoactive effects of cannabinoids: considerations for the therapeutic use of cannabinoid receptor agonists and antagonists. Int Immunopharmacol. 2010;10(5):547-55. https://doi.org/10.101 6/j.intimp.2010.02.012.

117. Klein TW, Newton C, Larsen K, Lu L, Perkins I, Nong L, et al. The cannabinoid system and immune modulation. J Leukoc Biol. 2003;74(4):486-96. https:// doi.org/10.1189/jlb.0303101.

118. LeCapitaine NJ, Zhang P, Winsauer P, Walker E, Vande Stouwe C, Porretta C, et al. Chronic $\Delta$-9-tetrahydrocannabinol administration increases lymphocyte CXCR4 expression in rhesus macaques. J Neurolmmune Pharmacol. 2011;6(4):540-5. https://doi.org/10.1007/s11481-011-9277-4.

119. Donald PJ. Marijuana smoking--possible cause of head and neck carcinoma in young patients. Otolaryngol Head Neck Surg. 1986;94(4):517-21. https:// doi.org/10.1177/019459988609400420.

120. Graef S, Choo CG, Warfield A, Cullen M, Woolhouse I. Small cell lung cancer in a 26-year-old man with significant Cannabis exposure. J Thorac Oncol. 2011;6(1):218-9. https://doi.org/10.1097/JTO.0b013e3181f77a20.

121. Kothadia JP, Chhabra S, Marcus A, May M, Saraiya B, Jabbour SK. Anterior mediastinal mass in a young marijuana smoker: a rare case of small-cell lung cancer. Case Rep Med. 2012;2012:754231.

122. Van Hoozen BE, Cross CE. Marijuana. Respiratory tract effects. Clin Rev Allergy Immunol. 1997;15(3):243-69. https://doi.org/10.1007/BF02737700

123. Ablasser A. Structures of STING protein illuminate this key regulator of inflammation. Nature. 2019;567(7748):321-2. https://doi.org/10.1038/d41586019-00707-8.

124. Ablasser A, Chen ZJ. cGAS in action: Expanding roles in immunity and inflammation. Science. 2019;363(6431):eaat8657z.

125. Gluck S, Guey B, Gulen MF, Wolter K, Kang TW, Schmacke NA, et al. Innate immune sensing of cytosolic chromatin fragments through cGAS promotes senescence. Nat Cell Biol. 2017;19(9):1061-70. https://doi.org/10.1038/ncb3 586.

126. Luecke S, Holleufer A, Christensen MH, Jonsson KL, Boni GA, Sorensen LK, et al. CGAS is activated by DNA in a length-dependent manner. EMBO Rep. 2017;18(10):1707-15. https://doi.org/10.15252/embr.201744017.

127. Shang G, Zhang C, Chen ZJ, Bai XC, Zhang X. Cryo-EM structures of STING reveal its mechanism of activation by cyclic GMP-AMP. Nature. 2019; 567(7748):389-93. https://doi.org/10.1038/s41586-019-0998-5.

128. Yang $H$, Wang $H$, Ren J, Chen $Q$, Chen ZJ. cGAS is essential for cellular senescence. Proc Natl Acad Sci U S A. 2017;114(23):E4612-20. https://doi. org/10.1073/pnas.1705499114.

129. Zhang C, Shang G, Gui X, Zhang X, Bai XC, Chen ZJ. Structural basis of STING binding with and phosphorylation by TBK1. Nature. 2019;567(7748): 394-8. https://doi.org/10.1038/s41586-019-1000-2.

130. Mackenzie KJ, Carroll P, Martin CA, Murina O, Fluteau A, Simpson DJ, et al. cGAS surveillance of micronuclei links genome instability to innate immunity. Nature. 2017;548(7668):461-5. https:/doi.org/10.1038/nature23449.
131. Crunfli F, Vrechi TA, Costa AP, Torrão AS. Cannabinoid receptor type 1 agonist ACEA improves cognitive deficit on STZ-induced neurotoxicity through apoptosis pathway and NO modulation. Neurotox Res. 2019;35(3): 516-29. https://doi.org/10.1007/s12640-018-9991-2.

132. Kumawat VS, Kaur G. Therapeutic potential of cannabinoid receptor 2 in the treatment of diabetes mellitus and its complications. Eur J Pharmacol. 2019; 862:172628. https://doi.org/10.1016/j.ejphar.2019.172628.

133. Mammana S, Cavalli E, Gugliandolo A, Silvestro S, Pollastro F, Bramanti P, Mazzon E. Could the Combination of Two Non-Psychotropic Cannabinoids Counteract Neuroinflammation? Effectiveness of Cannabidiol Associated with Cannabigerol. Medicina (Kaunas) 2019:(11):747:58.

134. Zeron-Medina J, Wang X, Repapi E, Campbell MR, Su D, Castro-Giner F, et al. A polymorphic p53 response element in KIT ligand influences cancer risk and has undergone natural selection. Cell. 2013;155(2):410-22. https://doi. org/10.1016/j.cell.2013.09.017.

135. Kanetsky PA, Mitra N, Vardhanabhuti S, Li M, Vaughn DJ, Letrero R, et al. Common variation in KITLG and at 5 q31.3 predisposes to testicular germ cell cancer. Nat Genet. 2009;41(7):811-5. https://doi.org/10.1038/ng.393.

136. Rapley EA, Turnbull C, Al Olama AA, Dermitzakis ET, Linger R, Huddart RA, et al. A genome-wide association study of testicular germ cell tumor. Nat Genet. 2009;41(7):807-10. https://doi.org/10.1038/ng.394.

137. Turnbull C, Rapley EA, Seal S, Pernet D, Renwick A, Hughes D, et al. Variants near DMRT1, TERT and ATF7IP are associated with testicular germ cell cancer. Nat Genet. 2010;42(7):604-7. https://doi.org/10.1038/ng.607.

138. Qin JX, Cai ZL, Yang YF, Xing JC, Zhuang X. Association between KITLG gene polymorphisms and testicular germ cell tumors: a systematic review and meta-analysis. Curr Med Sci. 2019;39(5):702-6. https://doi.org/10.1007/ s11596-019-2095-2.

139. Hill AB. The environment and disease: association or causation? Proc $R$ Soc Med. 1965;58(5):295-300. https://doi.org/10.1177/003591576505800503.

140. Reece AS, Wang W, Hulse GK. Pathways from epigenomics and glycobiology towards novel biomarkers of addiction and its radical cure. Med Hypotheses. 2018;116:10-21. https://doi.org/10.1016/j.mehy.2018.04. 011.

141. Nahas GG. Effects of hashish consumption in Egypt. N Engl J Med. 1972 ; 287(6):310. https://doi.org/10.1056/nejm197208102870621.

142. Mann P. Pot Safari, vol. 1. New York: Woodmere Press; 1982.

\section{Publisher's Note}

Springer Nature remains neutral with regard to jurisdictional claims in published maps and institutional affiliations.

Ready to submit your research? Choose BMC and benefit from:

- fast, convenient online submission

- thorough peer review by experienced researchers in your field

- rapid publication on acceptance

- support for research data, including large and complex data types

- gold Open Access which fosters wider collaboration and increased citations

- maximum visibility for your research: over $100 \mathrm{M}$ website views per year

At $\mathrm{BMC}$, research is always in progress.

Learn more biomedcentral.com/submission 